Revue des patrimoines

$25 \mid 2014$

Le patrimoine de la Grande Guerre

\title{
Archéologie de la Grande Guerre : les recherches archéologiques sur les gares régulatrices françaises et américaines de Marcilly-sur-Tille, 1914/1919 (Côte-d'Or)
}

\section{Frédéric Devevey}

\section{(2) OpenEdition}

\section{Journals}

Electronic version

URL: https://journals.openedition.org/insitu/11599

DOI: $10.4000 /$ insitu. 11599

ISSN: 1630-7305

\section{Publisher}

Ministère de la Culture

Electronic reference

Frédéric Devevey, "Archéologie de la Grande Guerre : les recherches archéologiques sur les gares régulatrices françaises et américaines de Marcilly-sur-Tille, 1914/1919 (Côte-d'Or)", In Situ [Online], 25 | 2014, Online since 16 December 2014, connection on 15 February 2023. URL: http:// journals.openedition.org/insitu/11599; DOI: https://doi.org/10.4000/insitu.11599

This text was automatically generated on 29 September 2020

Creative Commons - Attribution-NonCommercial-NoDerivatives 4.0 International - CC BY-NC-ND 4.0 https://creativecommons.org/licenses/by-nc-nd/4.0/ 


\section{Archéologie de la Grande Guerre : les recherches archéologiques sur les gares régulatrices françaises et américaines de Marcilly-sur-Tille, 1914/1919 (Côte-d'Or)}

Frédéric Devevey

1 L'opération de diagnostic archéologique qui s'est déroulée en avril 2011 sur la commune de Marcilly-sur-Tille s'inscrit dans le cadre du Code du patrimoine. Cette opération a été prescrite par le service régional de l'archéologie de Bourgogne, à la suite de la présentation d'un dossier de permis d'aménager déposé par la commune de Marcilly-sur-Tille.

\section{Rappel historique sur la « gare régulatrice » et le « camp américain »}

2 Implantée aux confins des départements de la Côte-d'Or et de la Haute-Marne, la gare de Marcilly-sur-Tille ${ }^{1}$ doit en partie son existence à la Compagnie de l'Est et au développement $d u$ chemin de fer sur le tronçon Dijon - Neufchâteau à la fin du XIXe siècle. La compagnie PLM s'y implante également avant 1914.

Le déclenchement de la Première Guerre mondiale allait donner un rôle nouveau (et essentiel) à cette gare. En effet, cette dernière supporte sa pleine charge ferroviaire dès le 2 août 1914, avec la mise en application du plan de mobilisation générale et devient "gare régulatrice de communication », selon la désignation militaire.

4 Lors de la mobilisation générale, la gare régulatrice de Marcilly-sur-Tille / Is-sur-Tille dépend de la $\mathrm{II}^{\mathrm{e}}$ armée du général Curières de Castelnau. Elle doit acheminer 314084 hommes de troupes et 9361 officiers entre Lunéville et Toul. 
Du 10 septembre au 31 décembre 1914, de la bataille de la Marne à la stabilisation provisoire du front, le déroulement de la guerre va changer insensiblement de nature. Désormais, le trafic ferroviaire, lié à la mobilité des troupes, va devoir assurer le ravitaillement et l'acheminement des munitions vers le front.

En ce qui concerne la II ${ }^{\mathrm{e}}$ armée (et la gare de Marcilly-sur-Tille), les transports viennent des secteurs de Toul et de Nancy. Pour donner un aperçu du trafic, du 7 au 24 septembre 1914, 443 trains se succèdent en gare (déchargement et chargement vers les différents points $\mathrm{du}$ front), soit sans discontinuer, plus d'un train par heure... La quantité de convois ferroviaires qui sont passés par Marcilly, notamment du 25 août au 13 septembre 1914, manifeste d'une façon remarquable la puissance stratégique du chemin de fer (fig. 1).

Figure 1

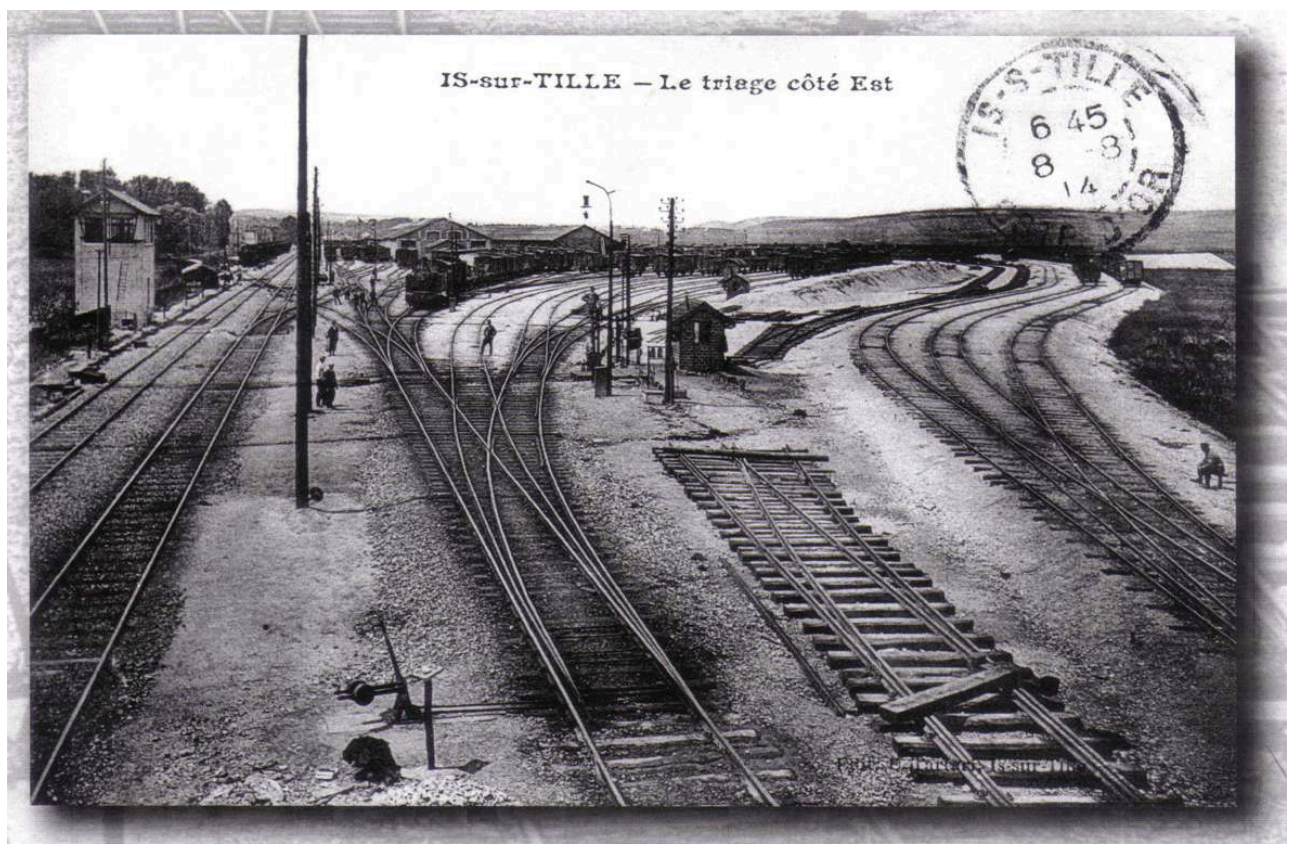

Carte postale de la gare de triage de «Is-sur-Tille», postée par un soldat en transit, le 8 août 1914. La photo a été prise avant le déclenchement de la guerre et présente l'état de la gare avant ses profonds remaniements. Les deux grands entrepôts visibles au $3^{e}$ plan ont été retrouvés lors de l'opération de diagnostic de 2011. Noter que les voies sont installées sur des remblais composés de graves de rivières locales. L'établissement du camp américain en 1917 (sur la droite du cliché) va nécessiter la mise en place d'un remblai de plusieurs hectares.

COLL. F. DEVEVEY. () US ARMY ARCHIVES.

7 Pour la durée de la guerre, la gare devint un vaste chantier en perpétuelle réorganisation. Au début du conflit, tout est à créer : ateliers pour l'artillerie, le génie, abris pour les matériels et la pharmacie, ce qui correspond à environ $1700 \mathrm{~m}^{2}$ de locaux, portés à plus de $4000 \mathrm{~m}^{2}$ à la fin de 1915. Un service postal aux armées sera également mis en place. Des voies de triage sont ajoutées. En 1915, la charge de la gare diminue considérablement en raison de l'évolution de la guerre et du déplacement des lieux de batailles.

8 Mais l'offensive sur Verdun en 1916 va nécessiter l'envoi de nombreux renforts en hommes et en matériel, redonnant à la gare régulatrice un nouvel essor. De nombreux 
régiments vont en effet transiter par Marcilly-sur-Tille avant d'être envoyés à Verdun. Pour une grande majorité de ces hommes, il s'agit d'un aller simple... (fig. 2)

Figure 2

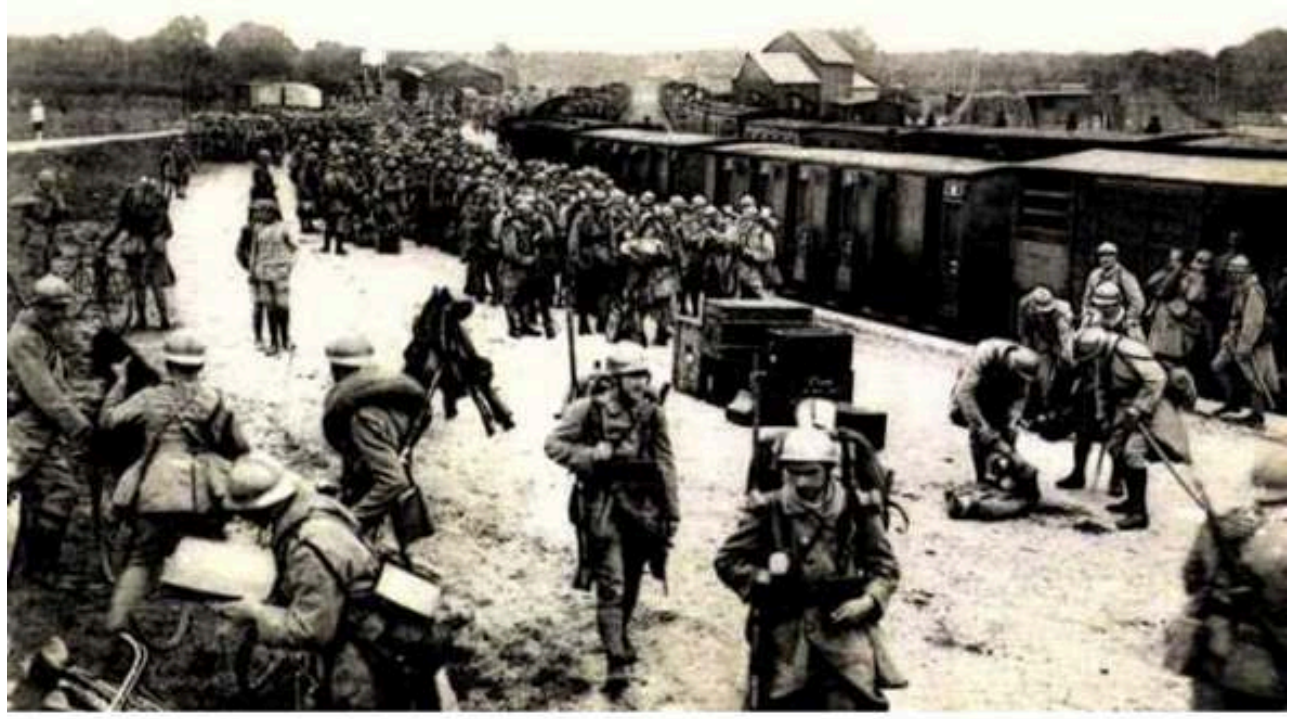

Arrivée d'un train régimentaire en provenance de Marcilly-sur-Tille, 1916.

Carte postale, coll. F. Devevey. (c) Frédéric Devevey.

\section{7 : l'entrée en guerre des États-Unis d'Amérique et la création de la « base avancée américaine $n^{\circ} 1$ à Is- sur-Tille/Marcilly-sur-Tille»}

9 Après 32 mois de neutralité, les États-Unis d'Amérique déclarent la guerre à l'Allemagne le 6 avril 1917. Disposant dans un premier temps d'effectifs et de matériel militaire limités, l'armée américaine fait appel à ses immenses ressources industrielles, prévoyant en effet que le conflit se prolongerait jusqu'en 1922 !...

10 Les ports français de Rochefort, Nantes, Saint-Nazaire et Brest sont choisis pour recevoir troupes et matériel en provenance des États-Unis (7000 à 9000 hommes et 20 000 tonnes de matériel par jour).

11 Cependant, il fallait déterminer le lieu où implanter une grande base avancée équipée de vastes entrepôts et d'une gare régulatrice pour desservir les unités américaines.

12 Le site de Marcilly-sur-Tille / Is-sur-Tille fut retenu rapidement car il offrait un large espace, quasiment plat, à proximité d'un réseau ferroviaire somme toute peu engorgé. Sans rentrer dans le détail de la construction du camp et de la gare américaine, il est utile de mentionner qu'il fallut assécher et remblayer les marais de la Tille sur une épaisseur allant parfois de 2,50 $\mathrm{m}$ à $3 \mathrm{~m}$. Pour cela, on déversa sur la bordure nord de la gare régulatrice française des centaines de tonnes de scories, vidanges de machines à vapeur, remblais divers, afin de prolonger sa plateforme pour la mettre de niveau avec les installations américaines. Des excavatrices importées des États-Unis furent 
employées pour extraire les graviers de la Tille, utilisés comme ballast. Certaines de ces fosses furent ensuite comblées avec des matériaux de rejet.

En moins de six mois, les Américains mirent en place une base de presque 20 hectares. À la signature de l'armistice, le site comportait $175 \mathrm{~km}$ de voies, 390 entrepôts, 250 baraquements et plus de 600 quais de débarquement. Près de deux millions de soldats américains et environ 4 millions de tonnes de fret sont passés dans les deux sens, entre l'automne 1917 et le printemps 1920. Il ne faudra que quelques mois pour que le camp «Williams » et l'ensemble de ses aménagements soient entièrement démantelés.

\section{Une source historique originale : le film américain de 1917-1918}

14 Grâce au précieux concours de la Société d'histoire Tille - Ignon (SHTI) et plus particulièrement à l'aide de $\mathrm{M}$. Michel Valentin, nous avons pu obtenir la copie d'un film qui correspond en fait au montage d'au moins trois séquences tournées en 1917 et 1918 par l'armée américaine. Le film est muet et ne comporte aucune explication ou légende. L'étude de ce dernier nous a permis d'obtenir certaines informations qui se sont avérées précieuses pour la compréhension de l'organisation générale du camp américain et l'identification de certains bâtiments. Cependant, seule une séquence, prise depuis le sommet du mont de Marcilly-sur-Tille vers le nord, livre la vue générale (mais assez éloignée) de la gare régulatrice française. La majeure partie du film traite des différentes étapes des aménagements des gares et camps américains (fig. 3, 4).

Figure 3

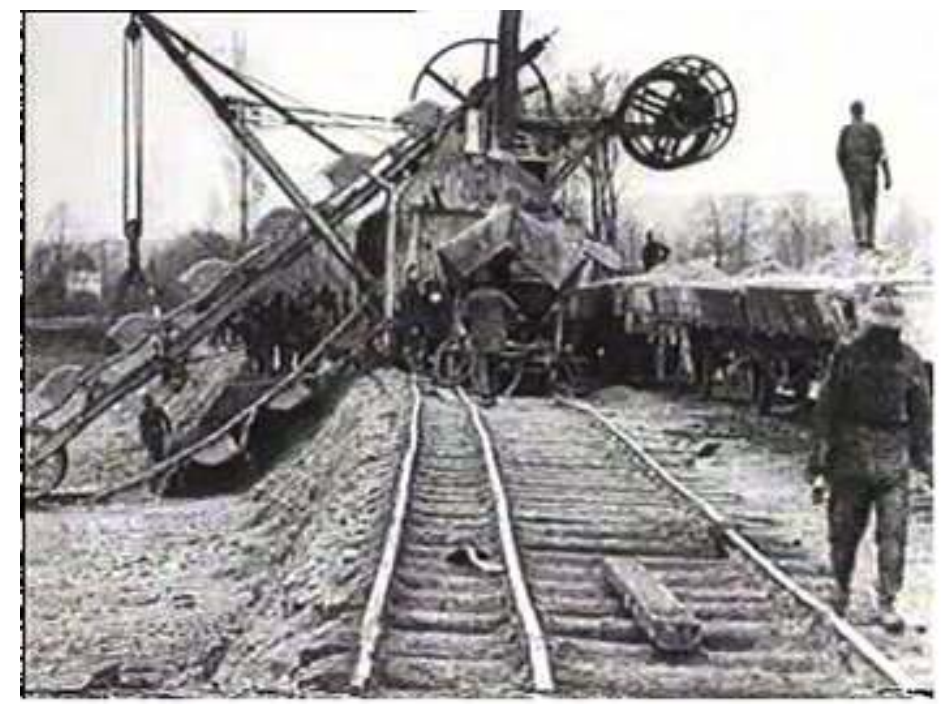

Extraction des graviers de la vallée de la Tille lors de la mise en place du camp américain (extrait du film).

(c) US Army archives. 


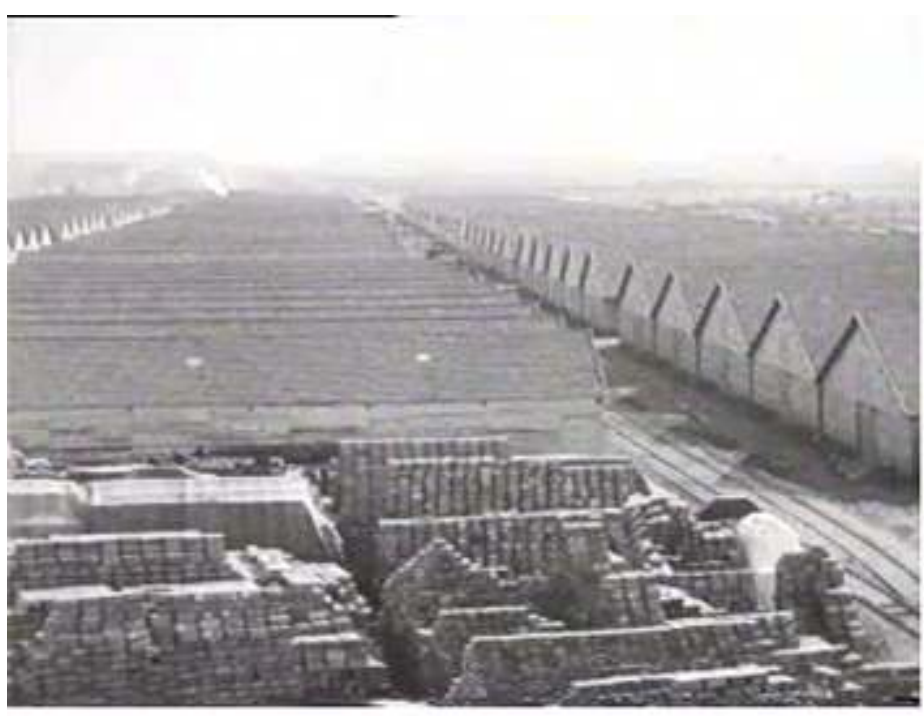

Vue générale du camp américain, vue vers le sud-est (extrait du film).

(c) US Army archives.

\section{Des zones d'extraction}

Des aires d'extraction ont été décelées. La bordure sud d'une vaste aire d'extraction de graviers a pu être clairement reconnue dans la partie nord de l'emprise. Elle se caractérisait par la présence de remblais de chemins de fer pouvant dépasser une épaisseur de $2 \mathrm{~m}$. La disposition des remblais indique la volonté de combler rapidement cette vaste excavation qui se situait au nord de la gare régulatrice française.

La présence incontestable de matériel militaire américain prouve que le comblement n'est pas antérieur à l'automne 1917, date de mise en service des premiers aménagements de la gare "géante » américaine (appelée officiellement base avancée américaine $\mathrm{n}^{\circ} 1$ ). Les sources historiques semblent nous renseigner sur la nature de cette gravière. Tout d'abord, les réfections et aménagements nécessaires et continus de la gare régulatrice française de 1914 à 1917 ont nécessité l'utilisation d'une grande quantité de graviers et galets de rivière, utilisés comme remblais de plateformes et de ballasts.

17 La construction de la base américaine exigea une quantité encore plus importante de matériaux. Au sud-ouest, dans la plaine de l'Ignon, sur les communes d'Is-sur-Tille et Marcilly-sur-Tille, des dragues (montées sur des rails) exploitèrent durant plusieurs semaines les bancs de graviers, notamment en bordure immédiate de la gare française, sur des profondeurs pouvant dépasser les 3 à $4 \mathrm{~m}$, suivant la profondeur et l'épaisseur de ces derniers. Les excavations furent alors rapidement rebouchées avec des matériaux abondants provenant principalement de l'activité ferroviaire, dont les scories et le mâchefer issus de la vidange des nombreuses machines à vapeur qui transitaient ${ }^{2}$ par la gare. 


\section{Un fossé défensif}

Cette structure se présentait sous la forme d'une tranchée de 1,20 m de large, d'environ $1,60 \mathrm{~m}$ de profondeur et de plus de $30 \mathrm{~m}$ de long. Son tracé en créneaux est caractéristique des fossés défensifs anti-éclats. Sa présence pourrait être liée à une structure militaire de défense antiaérienne.

19 Étant donné l'éloignement du site par rapport aux lignes de front, le seul usage de cette tranchée serait de constituer une protection contre un danger venu du ciel. Là encore, les sources françaises font défaut et seules les archives américaines peuvent apporter quelques informations.

20 Au moins quatre batteries antiaériennes américaines furent installées à partir de juillet 1917. Elles étaient accompagnées de puissants projecteurs ainsi que d'appareils d'écoute, destinés à repérer l'arrivée éventuelle d'aéronefs (avions ou « zeppelins »). La localisation exacte de ces installations n'est pas connue. Nous savons seulement que l'une d'entre elles était implantée sur le mont de Marcilly-sur-Tille. Cependant, le secteur d'Is-sur-Tille n'eut jamais à subir la moindre attaque. Seuls quelques tirs d'exercice furent pratiqués ponctuellement.

\section{Une vaste zone de dépotoir}

21 Une grande fosse dépotoir se singularisait par sa position au sein même de la gare régulatrice. Les zones de remblais - dépotoirs les plus riches - les plus épaisses sont localisées au nord de la parcelle, selon une ligne est-ouest qui semble correspondre à l'ancienne bordure nord de la gare régulatrice française, par la suite prolongée et remblayée en vue de la mise en place du camp américain.

Cette grande fosse, riche en déchets de toutes sortes (céramiques, vaisselle de cantine, verre, petit mobilier, etc.) pourrait éventuellement correspondre à une « cave » ou une ancienne structure de stockage comme il pouvait en exister régulièrement sous certains bâtiments de service à usage militaire, tels que les cantines ou réfectoires. Ce type d'aménagement est d'ailleurs à plusieurs reprises évoqué dans l'ouvrage publié par la SHTI ${ }^{3}$. Une carte postale datant de 1914, prise au cœur de la gare régulatrice (avant que la censure militaire ne prenne des mesures) pourrait éventuellement avoir été prise au droit de cette zone.

\section{Les entrepôts de la gare régulatrice}

23 Les fondations de longs bâtiments ont été mises au jour. Elles peuvent être identifiées comme appartenant à une série de grands entrepôts visibles à la fois sur la carte postale «Triage Est » de 1914, ainsi que sur le film de l'armée américaine et la photo aérienne de 1918.

Cependant, contrairement au camp américain, on connaît assez mal les détails de l'organisation des installations de la gare régulatrice française. On sait qu'il existait au début de la guerre des bureaux, un service d'intendance, une station de téléphone et de télégraphe et une infirmerie. Le long des "quais militaires» sont mentionnés des "cantines avec réserves", des baraquements divers. La gare française comportait également un atelier pour le génie ( $5^{\mathrm{e}}$ régiment) et pour l'artillerie, d'abris 
(souterrains ??) pour les armes, munitions et la pharmacie, d'un centre de tri postal d'une surface de plus de $4000 \mathrm{~m}^{2}$ fin 1915 . Deux grands entrepôts parallèles sont connus dès 1914, à l'est de la gare de triage. Les dimensions étaient de $152 \mathrm{~m}$ de long pour $15 \mathrm{~m}$ de large environ.

\section{Le mobilier archéologique, nature et tentatives d'interprétation}

\section{La céramique}

La vaisselle mise au jour durant le diagnostic, issue des niveaux du début du conflit, semble correspondre à de l'approvisionnement en provenance de Lorraine, destiné aux cantines militaires installées le long des voies de la gare régulatrice. L'important lot issu de certains sondages semble provenir de caisses tombées à terre si l'on en juge par l'aspect neuf et très homogène du matériel. Il s'agit de vaisselle commune, sans aucune trace de décors particuliers (si l'on fait exception de la tasse " aux lanciers ", datée des années 1870 et dont la présence est sans doute erratique). La majeure partie de la vaisselle mise au jour dans les niveaux antérieurs à 1916 provient donc de Lorraine et plus particulièrement de Badonviller / Pexonne. Ces productions sont interrompues par les destructions liées à la guerre dès la mi-août 1914 (fig. 5).

Figure 5

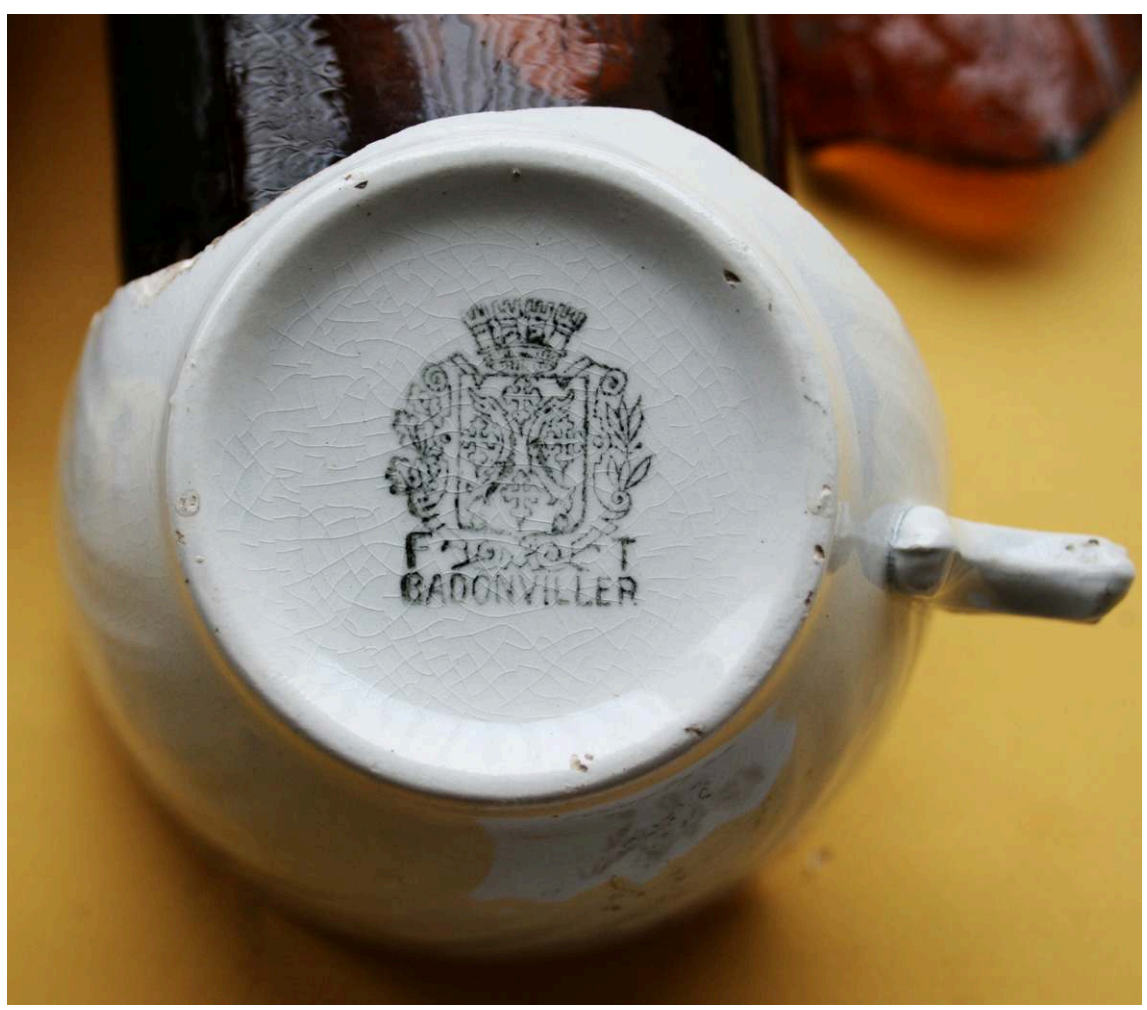

Tasse de Badonviller.

Phot. Devevey, Frédéric. (C) Inrap. 
« Badonviller »

Datation des objets : avant le 12 août $1914^{4}$.

La faïencerie fut construite en 1897 par les premiers ouvriers de l'usine, sur un terrain proche des deux gares, en bordure de la rivière Blette. La Première Guerre mondiale entraîna l'arrêt complet du travail et de très importantes destructions (fig. 6).

Figure 6

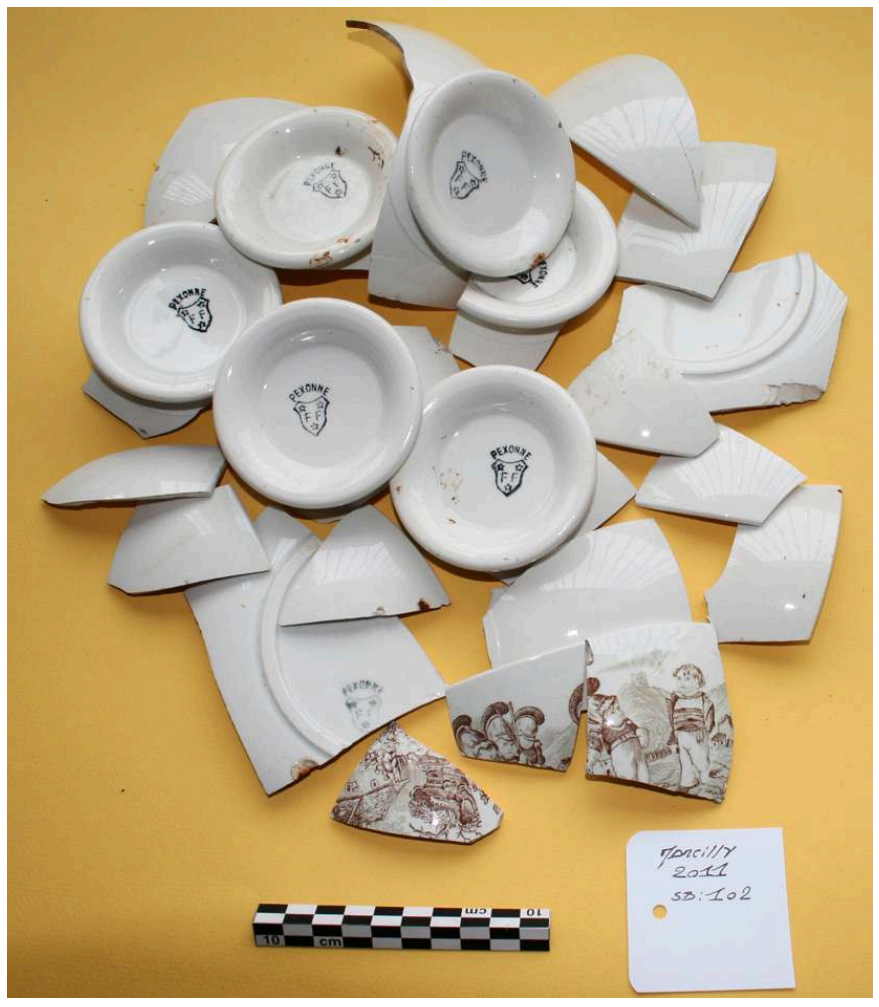

LOT DE CÉRAMIQUES DE PEXONNE « F.F. 》.

Phot. Devevey, Frédéric. (C) Inrap.

« Pexonne FF » = Pexonne Fenal Frères (Inv. C.2010/217-100, 102)

La fabrique Pexonne Fénal Frères (Pexonne F.F.) était aussi implantée à Badonviller et appartenait également à la famille Fénal.

\section{Quelques réflexions sur les approvisionnements de la gare régulatrice de Marcilly-sur-Tille-sur-Tille depuis Badonviller}

La ville de Badonviller est au cœur de l'offensive dès les premiers jours de la guerre. Les 9-10 août, une petite offensive allemande locale se développe dans le secteur Blâmont Cirey-sur-Vezouze. Le $16^{\mathrm{e}}$ régiment bavarois s'engage dans ce secteur presque dépourvu de défenseurs et ravage tout sur son passage. Le 12 août au matin, le $20^{\mathrm{e}}$ chasseurs accroche une de ses compagnies, mais doit reculer sous l'assaut du régiment. 
Dès le 10 août 1914, les habitants eurent l'impression que des événements graves se déroulaient autour d'eux. Parux $(6 \mathrm{~km})$ en entier brûlait, Bréménil $(3 \mathrm{~km})$ était incendié. Le mardi 11 août le feu était à Malgréjean, à 1500 mètres de Badonviller, où l'ennemi était parvenu. Les premiers obus sifflaient sur la ville. Le lendemain 12 août, après un combat qui dura de 5 heures à 9 heures du matin, 4 heures pendant lesquelles le $20^{\text {ème }}$ bataillon de chasseurs à pied résista héroïquement à des troupes bien supérieures en nombre, les Bavarois entrèrent en force à Badonviller. À ce moment quelques chasseurs en retraite tirèrent sur les colonnes qui venaient renforcer l'ennemi. Furieux de cette fusillade, les allemands alléguèrent que des civils avaient tiré sur eux, prétexte mensonger toujours invoqué pour justifier une série d'exécutions sommaires ${ }^{5}$.

À cette date, les productions des faïenceries cessent toute activité jusqu'à l'armistice de 1918. De ce fait, les derniers arrivages « massifs » de vaisselle « Pexonne F.F. » à la gare régulatrice de Marcilly-sur-Tille s'interrompent avant la mi-août 1914, date à laquelle la région de Badonviller est occupée (fig. 7).

\section{Figure 7}

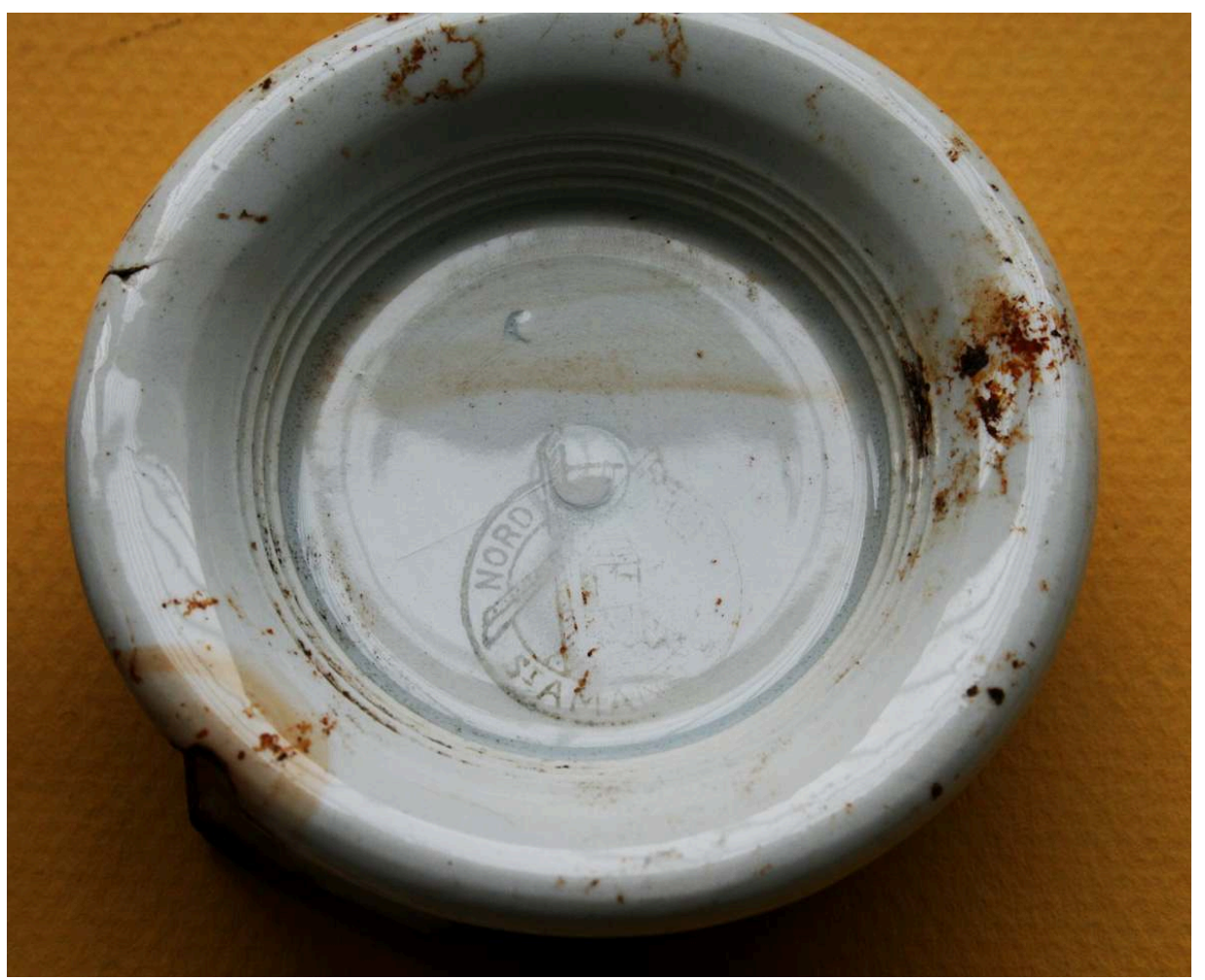

Fond de bol de Saint-Amand-et-Hamage Nord.

Phot. Devevey, Frédéric. (C) Inrap.

\section{«St. Amand et Hamage»}

Datation de l'objet : 1914 - 1918.

Dans le Nord, à $13 \mathrm{~km}$ de Valenciennes, Saint-Amand-les-Eaux réunissait les conditions favorables à l'implantation de faïenceries : voies d'eau, routes et forêts. La fabrication de faïence stannifère fut implantée à Saint-Amand en 1705 par Nicolas Desmoutiers, dont la manufacture fut dirigée par son fondateur puis par des membres de la famille Dorez, descendants de Barthélémy Dorez, céramiste à Lille. En 1896, la marque « Saint 
Amand et Hamage Nord» est déposée après la création d'une seconde usine à Wandignies-Hamage. Celle-ci prend une rapide extension. En 1900 est fondée près de la gare la «Société Amandinoise de Faïencerie ». Ces faïenceries seront les seules à maintenir leur activité pendant la Première Guerre mondiale.

D'autres objets en céramique ont été mis au jour dans les différents sondages. Il s'agit principalement d'objets utilitaires, voire techniques. Quelques exemples sont présentés ici (fig. 8).

Figure 8

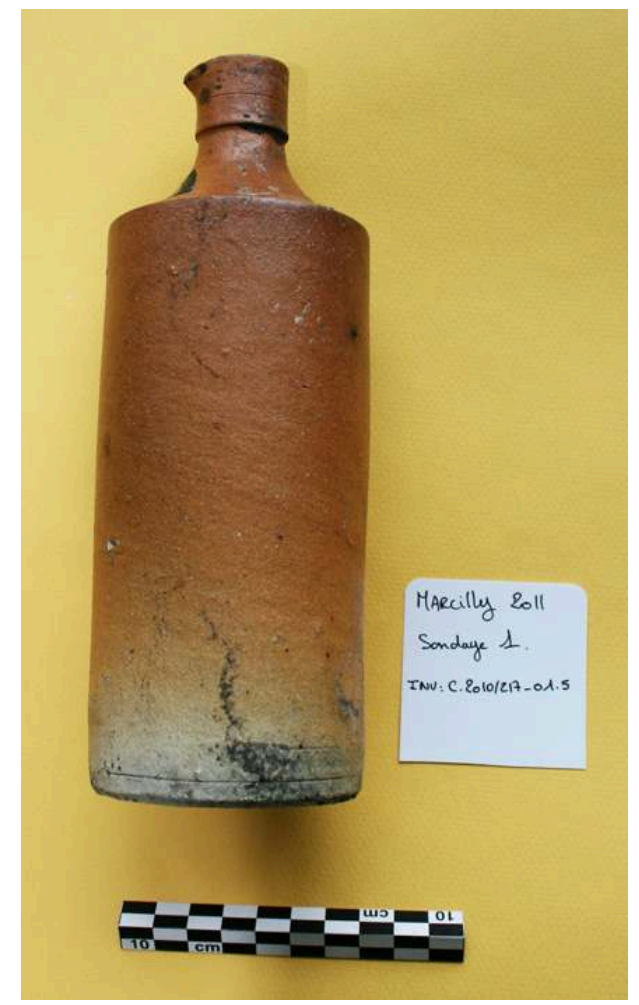

Bouteilles d'encre en grès provenant des sondages 1 et 19 .

Phot. Devevey, Frédéric. (c) Inrap.

\section{Les piles et accumulateurs}

Découverts en très grand nombre dans certains sondages de l'opération, de petits récipients cylindriques, parfois en forme de bouteille,, ont été mis au jour. Certains de ces tessons de pots en céramique étaient accompagnés de fragments de récipients en verre. Comme nous allons le voir, ces derniers étaient liés.

Deux types de piles / accumulateurs ont été identifiés sur le site. Il s'agit des modèles « LECLANCHE », « FERY » et des modèles « BUNSEN » (fig. 9, 10, 11). 
Figure 9

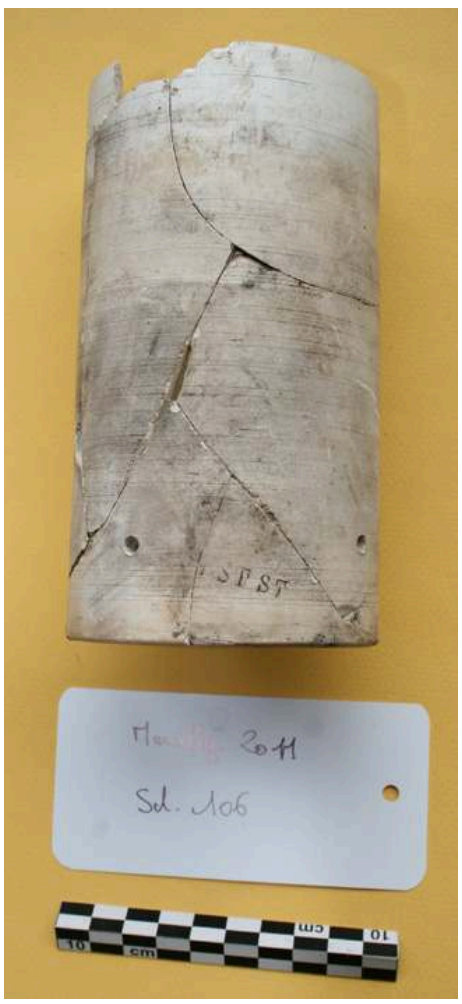

Éléments de batteries d'accumulateurs de type LECLANCHE qui servaient entre autre à l'éclairage des wagons postaux (voir infra "L'éclairage nocturne »). Ces derniers ont été construits sous licence pour la Compagnie Est des chemins de fer.

PHOT. DEVEVEY, FRÉDÉRIC. C INRAP. 
Figure 10

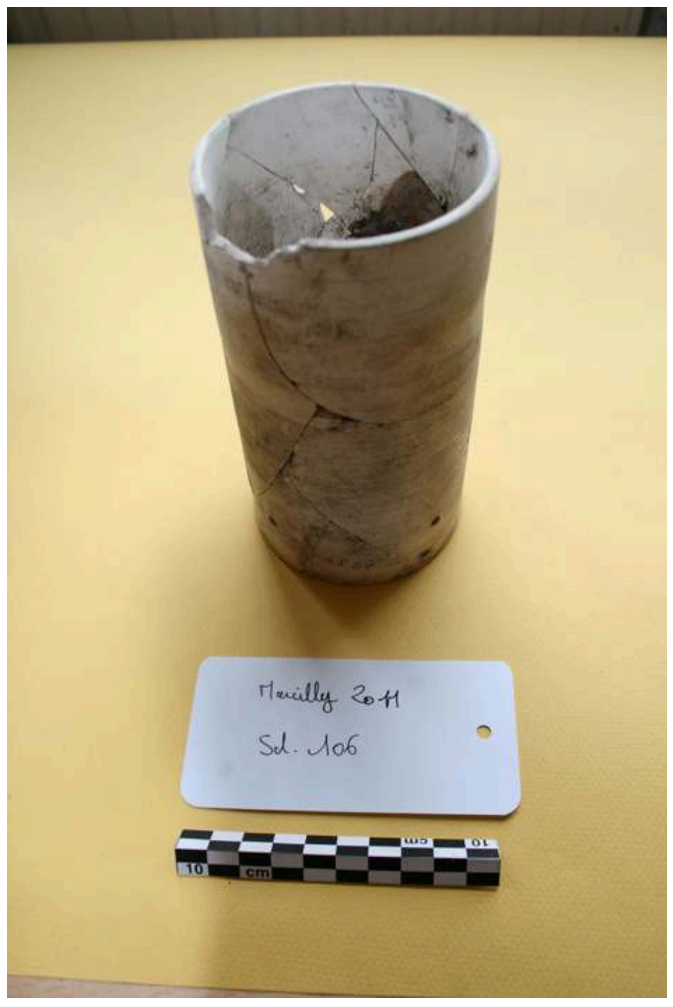

Éléments de batteries d'accumulateurs de type LECLANCHE qui servaient entre autre à l'éclairage des wagons postaux (voir infra "L'éclairage nocturne »). Ces derniers ont été construits sous licence pour la Compagnie Est des chemins de fer.

PHOT. DEVEVEY, FRÉDÉRIC. (C) INRAP. 
Figure 11

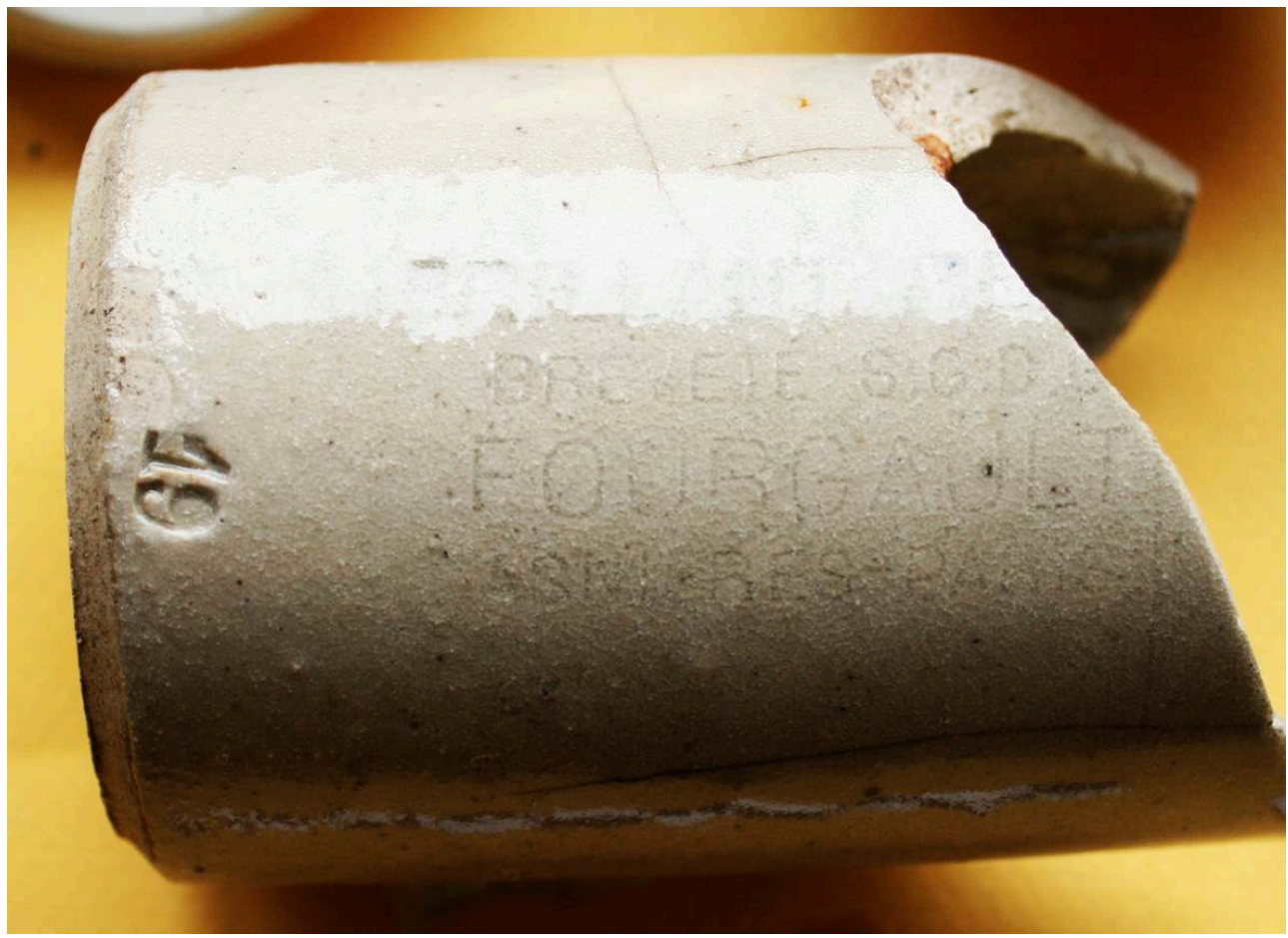

Élément de pile «bouteille » de type FERY ou BENSE. Noter le marquage caractéristique : «Breveté S.G.D.G. ». La marque « Fourgault » correspond au fabriquant du récipient.

Phot. Devevey, Frédéric. (C) Inrap.

Le pôle négatif était constitué par un bâton de zinc plongé dans une solution de chlorure d'ammonium $(\mathrm{sel})^{6}$. Le pôle positif correspondait à un barreau de charbon enfermé dans un vase poreux, rempli d'un mélange de charbon en poudre et de manganèse. Ce sont ces fragments de vases et de barreaux qui ont été retrouvés en grand nombre dans les sondages (fig. 12). 
Figure 12

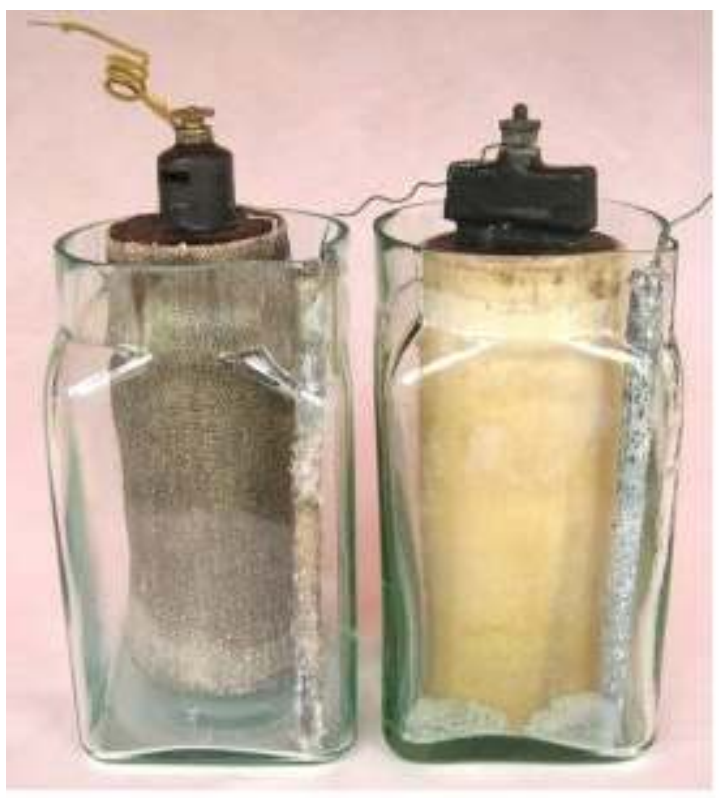

Deux modèles de type LECLANCHE. L'exemplaire de droite correspond aux éléments mis au jour à Marcilly-sur-Tille. Le récipient en verre contenait de l'eau salée.

Phot. Devevey, Frédéric. (c) Inrap.

Les modèles FERY et BUNSEN fonctionnaient selon un principe similaire mais pouvaient être mis en "batteries", soit dans des caisses en bois, des casiers ou même des locaux prévus à cet effet. Ils servaient à l'éclairage des wagons, ou à l'alimentation d'appareils plus « sophistiqués » tels que les postes de TSF ou les sémaphores lumineux (fig. 13).

Figure 13
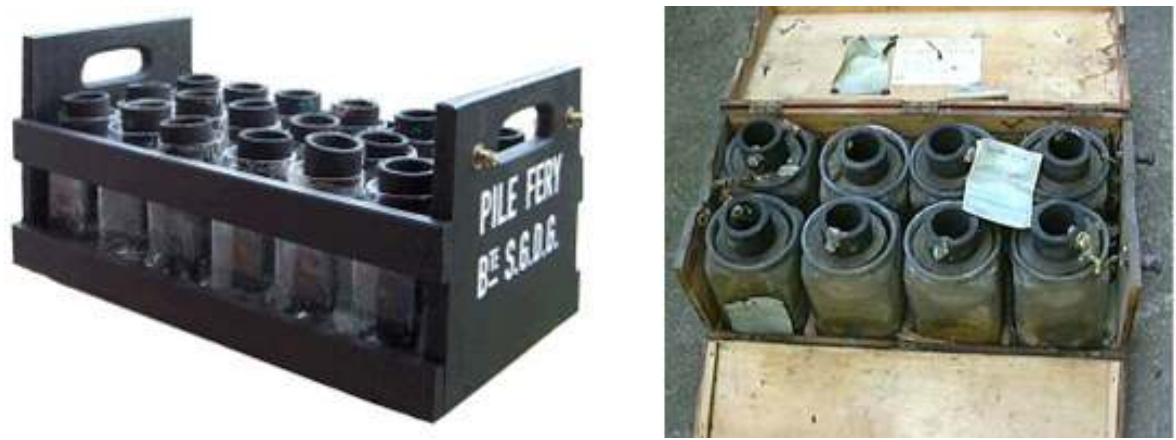

Exemples de piles en batteries FERY. L'exemple de droite était utilisé pour faire fonctionner les premiers postes de TSF militaires. Noter sur la caisse de droite la mention « Bte - S.G.D.G. ». Phot. Devevey, Frédéric. (c) Inrap.

\section{Le verre}

\section{Les boissons : la bière et le vin}

Contrairement au vin et à la "gnole» acheminés par wagons-citernes, une grande proportion de boissons de type bières et cidres distribuées aux troupes en transit dans les gares correspondaient à des productions locales. Les soldats pouvaient également 
s'approvisionner individuellement chez les commerçants ou l'habitant. Cependant il semble que des abus aient été pratiqués, d'où la distribution des consignes suivantes (fig. 14, 15) :

Figure 14

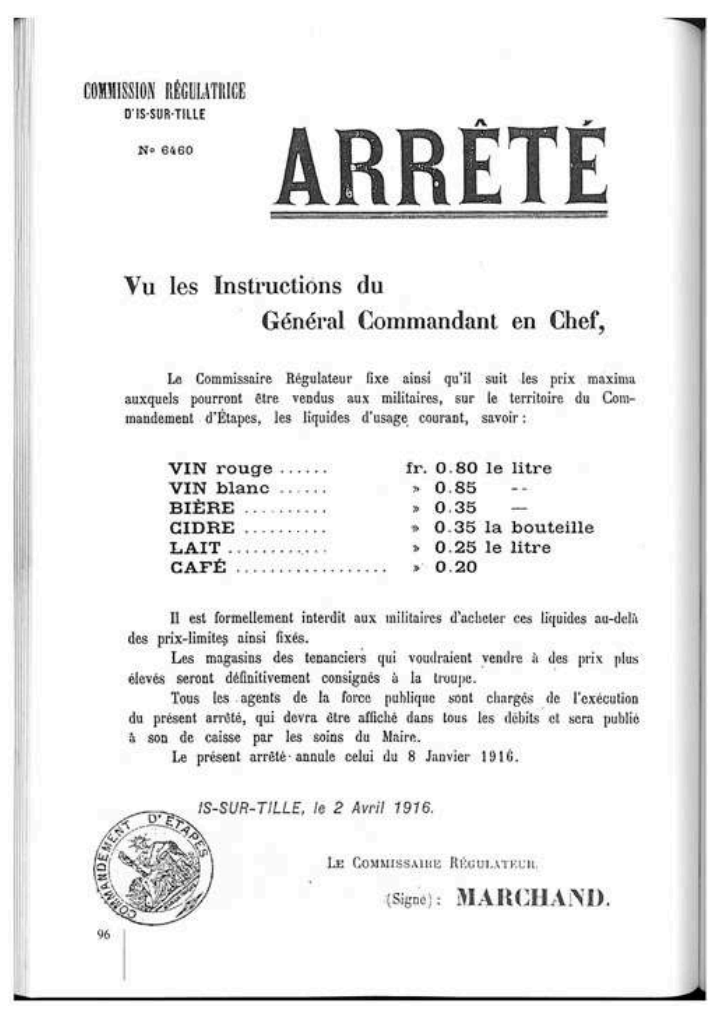

Arrêté de la Commission régulatrice d'Is-sur-Tille fixant les prix de vente des liquides aux militaires. COLL. F. DEVEVEY. @ FRÉDÉRIC DEVEVEY.

Figure 15

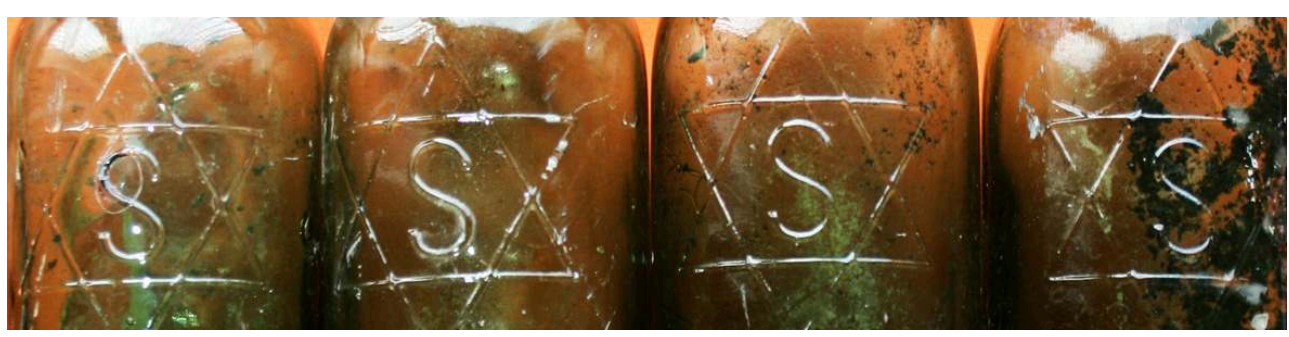

Lot de bouteilles de bières portant la marque d'un brasseur de la région d'Is-sur-Tille. Phot. Devevey, Frédéric. (C) Frédéric Devevey.

L'étoile représentée sur ces bouteilles, ressemblant à une étoile de David, est « l'étoile des brasseurs » qui est apparue à la fin du Moyen Âge et est devenue peu à peu le symbole de la bière. Il s'agit d'une représentation symbolique de l'alchimie brassicole mettant en œuvre les quatre éléments (terre, feu, eau, air) (fig. 16, 17). 
Figure 16
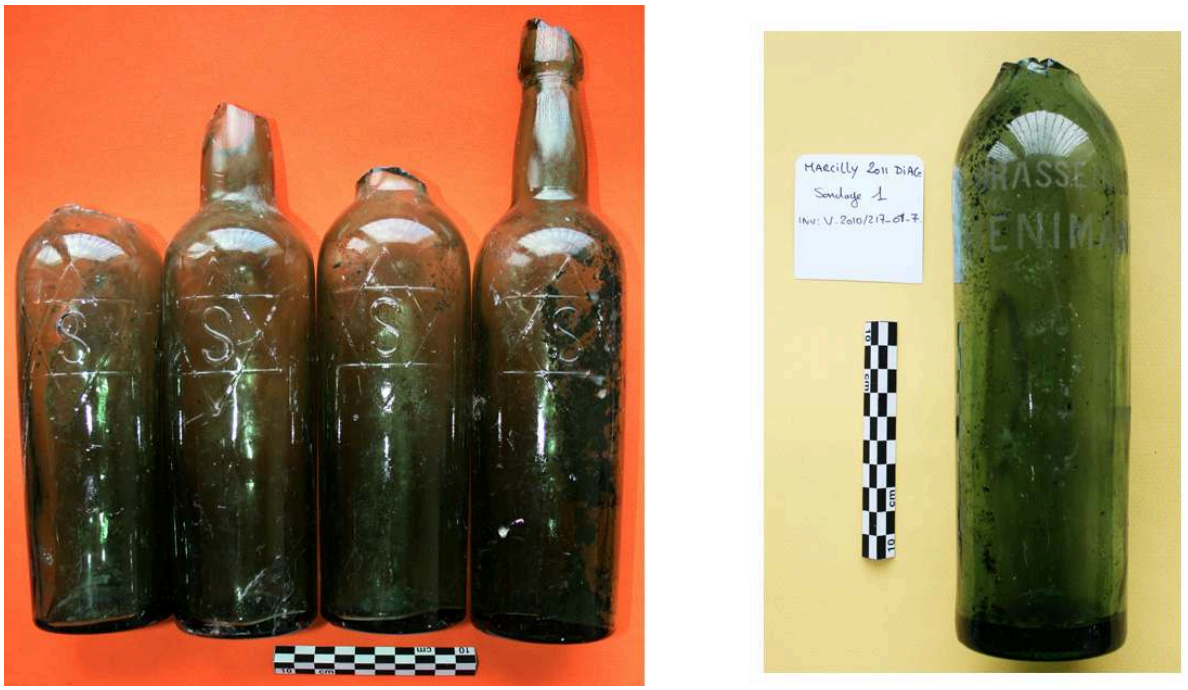

Lot de bouteilles de bières trouvées dans le sondage 005

Phot. Devevey, Frédéric. (c) Frédéric Devevey.

Figure 17
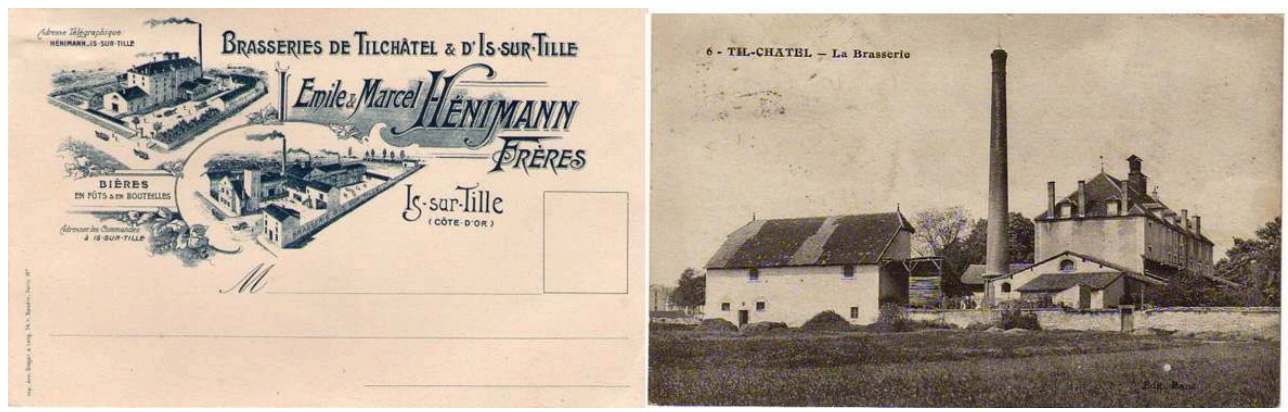

Cartes postales de la brasserie Henimann à Is-sur-Tille et Til-Châtel vers 1910.

Phot. Devevey, Frédéric. (c) Frédéric Devevey.

Encriers, flacons, etc.

(fig. 18, 19, 20, 21) 
Figure 18

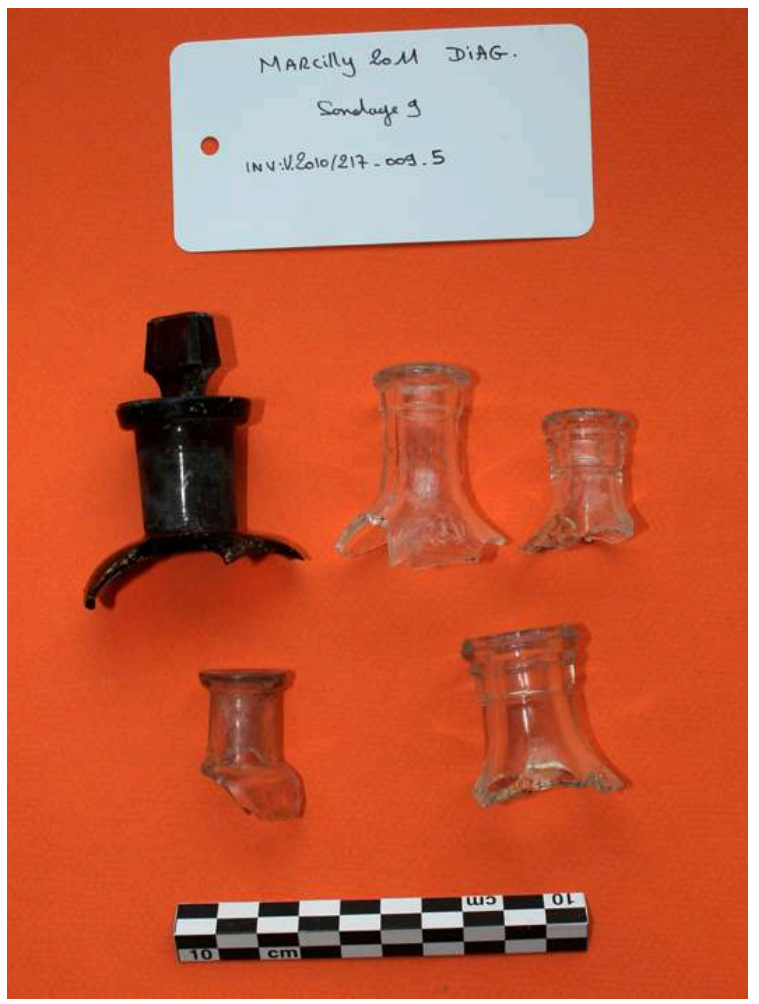

Divers éléments de flacons pharmaceutiques provenant du sondage 9.

Phot. Devevey, Frédéric. (c) Frédéric Devevey. 
Figure 19

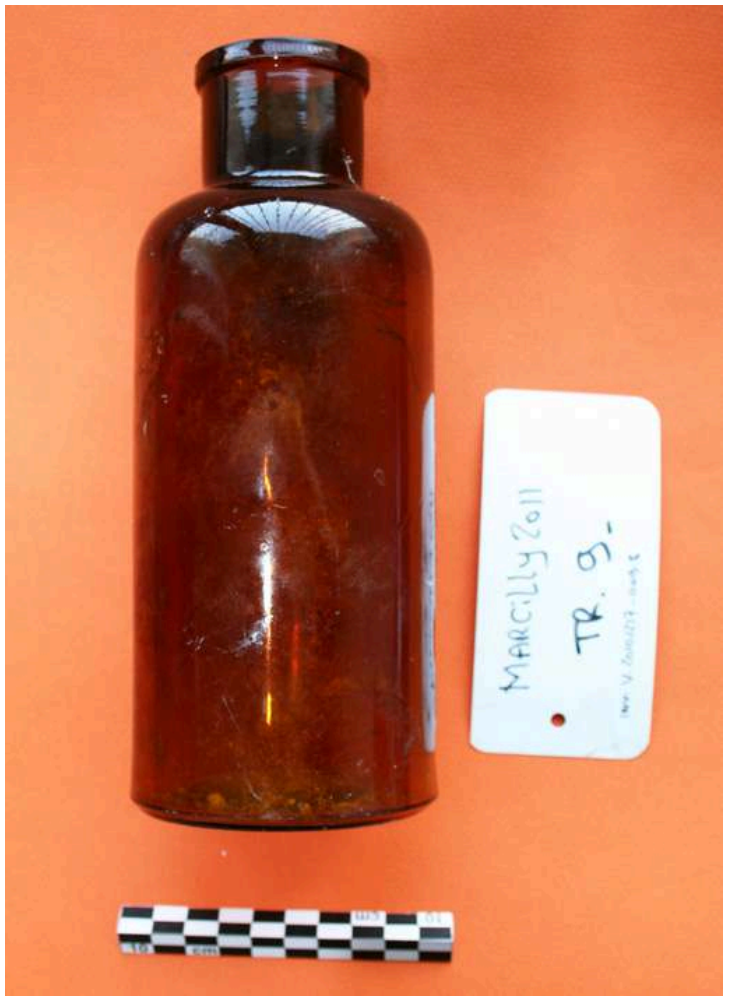

Grand flacon à désinfectant pharmaceutique.

Phot. Devevey, Frédéric. (c) Frédéric Devevey.

Figure 20

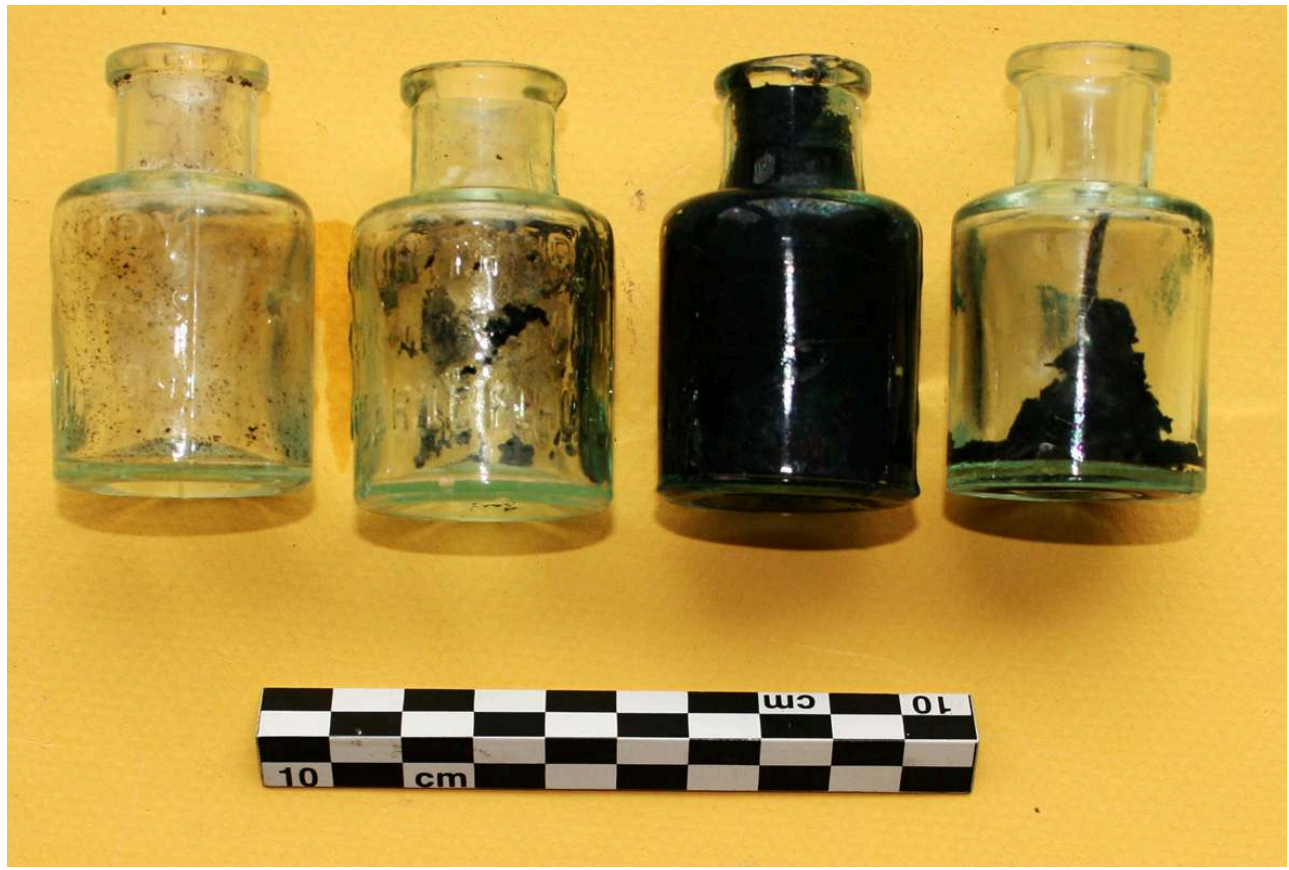

Sondage 74 : échantillon d'un lot de petites bouteilles d'encre en verre. Plus d'une centaine de fragments d'encriers a été mise au jour dans ce sondage. Leur présence pourrait résulter de la chute d'une caisse lors d'un déchargement. Ne sont présentés ici que les rares exemplaires restés intacts.

Phot. Devevey, Frédéric. (c) Frédéric Devevey. 
Figure 21

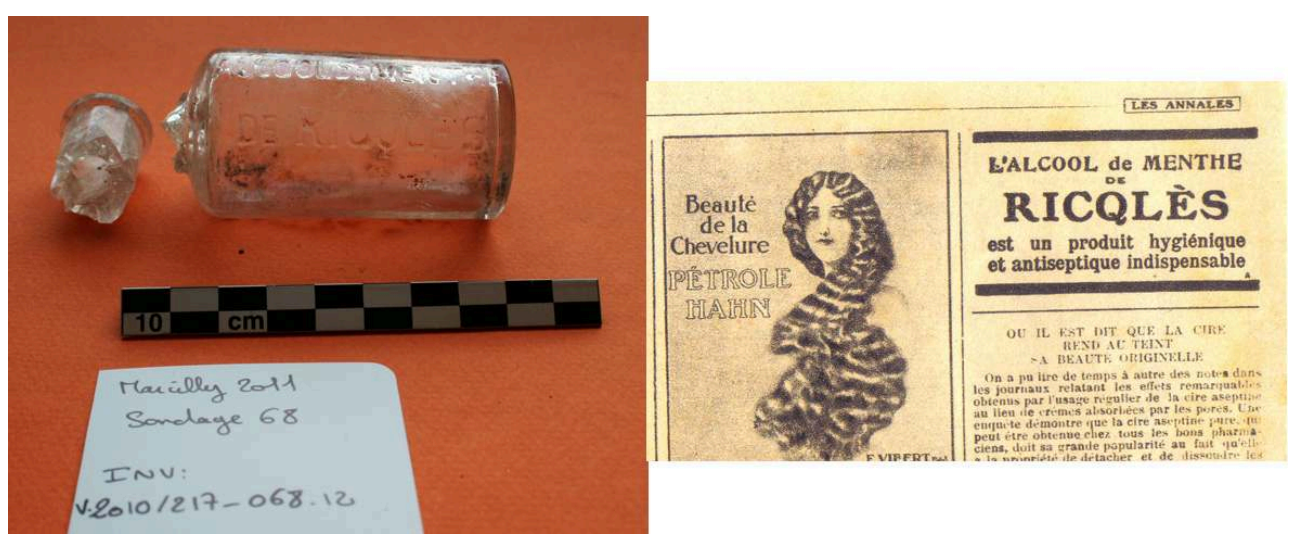

Flacon d'alcool de menthe « Ricqlès » et publicité dans Les Annales, septembre 1916. Comme beaucoup de produits d'hygiène, ces derniers étaient le plus souvent envoyés aux soldats dans des colis depuis l'arrière.

Phot. Devevey, Frédéric. (C) Frédéric Devevey.

\section{Le métal}

Énumérer dans le cadre de ce diagnostic les différents types d'objets ou fragments d'objets en métal mis au jour serait une véritable gageure; ne sont donc présentés ici que de très petits exemples d'échantillonnages, sachant que les objets vont du bouton de culotte au morceau de wagon ou de locomotive! Le recensement des objets présentés ci-après n'est donc pas exhaustif (fig. 22, 23). 
Figure 22

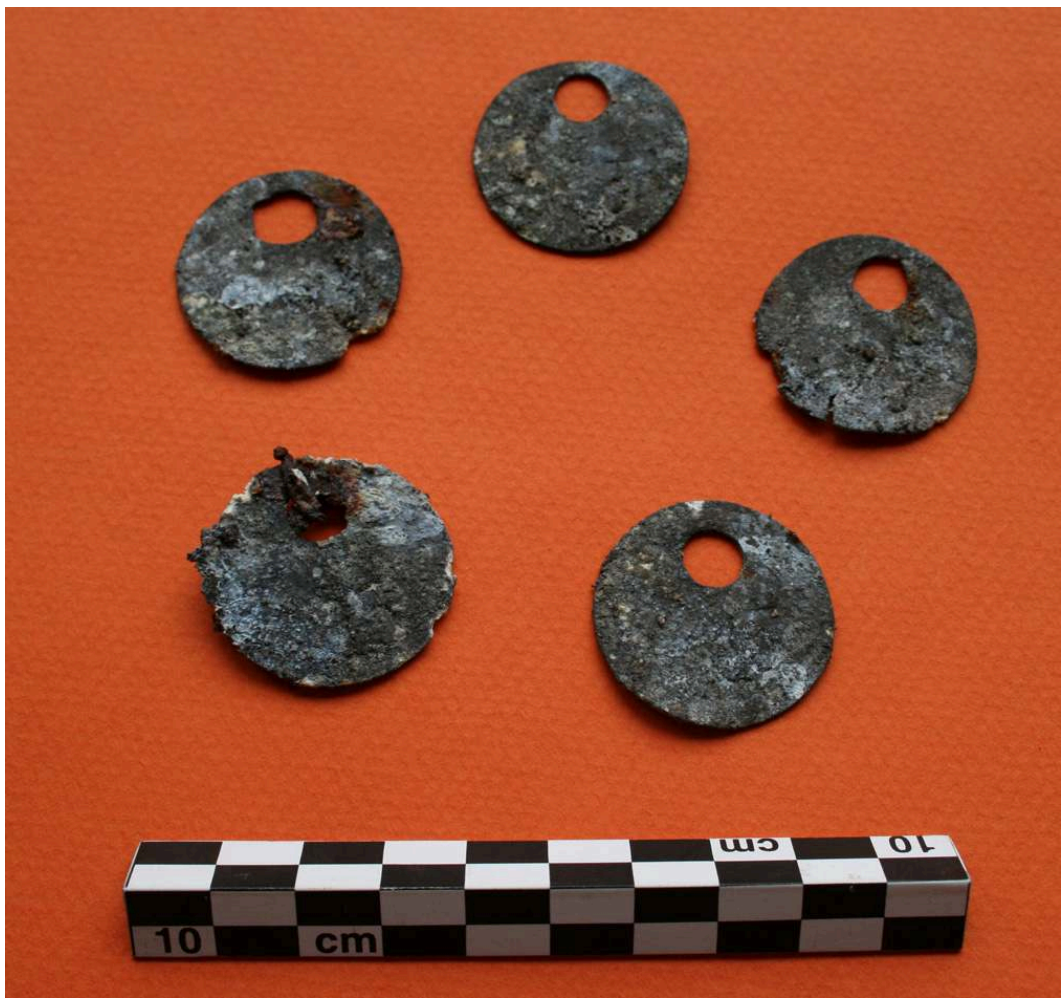

Médaillons dont certains sont numérotés « $+18+»$. Leur fonction est sans doute à mettre en relation avec le scellement de sacs de marchandises ou de courrier.

Phot. Devevey, Frédéric. (c) Frédéric Devevey.

Figure 23
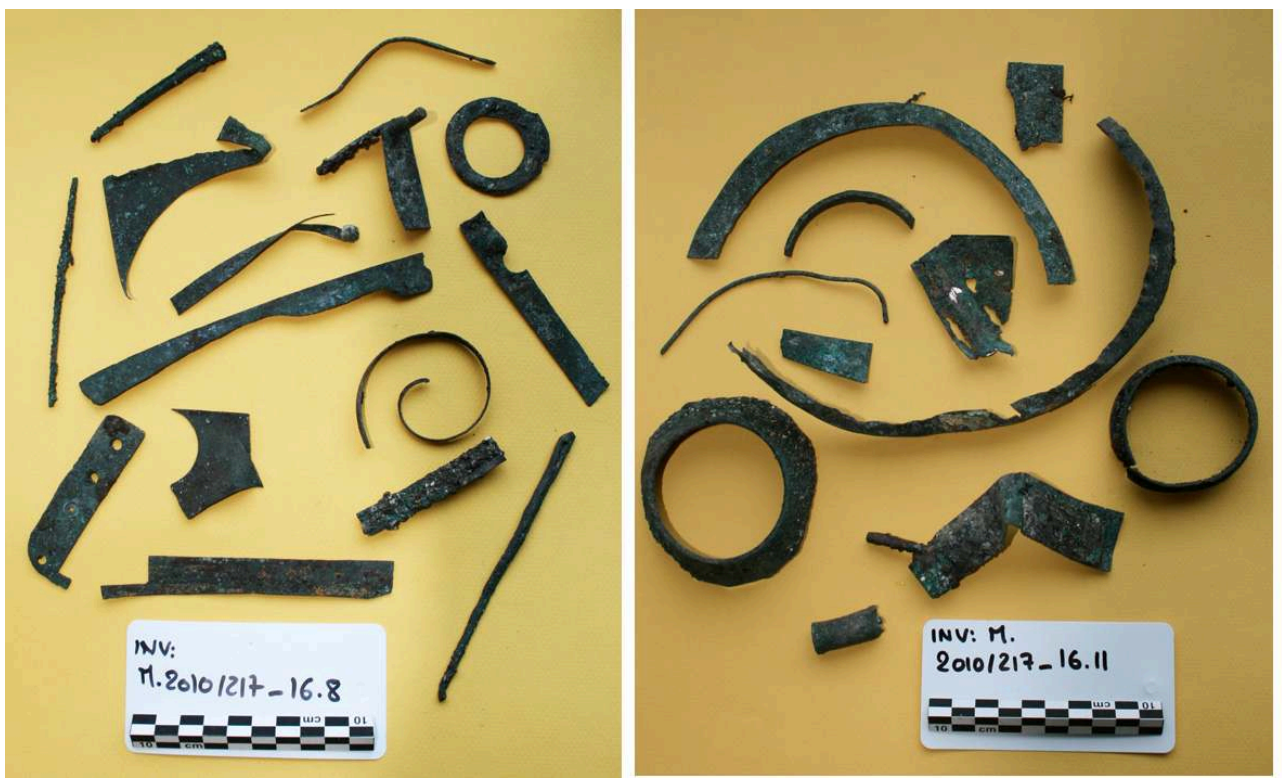

Divers éléments d'objets en métaux cuivreux récupérés et découpés. Plus d'une centaine de ces objets ont été découverts dans ce sondage.

Phot. Devevey, Frédéric. (C) Frédéric Devevey. 
Bien que le site se situe loin en arrière du front, les centaines de chutes de métal (alliages cuivreux) découverts dans le sondage 16 présentent vraiment de très grandes similitudes avec «l'artisanat de tranchée ». Il n'est pas impossible en effet que les hommes (Français ou Américains) stationnés à Marcilly-sur-Tille / Is aient utilisé une partie de leur temps libre à ce genre d'activité.

\section{Les boîtes de conserve et les rations}

(fig. 24)

\section{Figure 24}

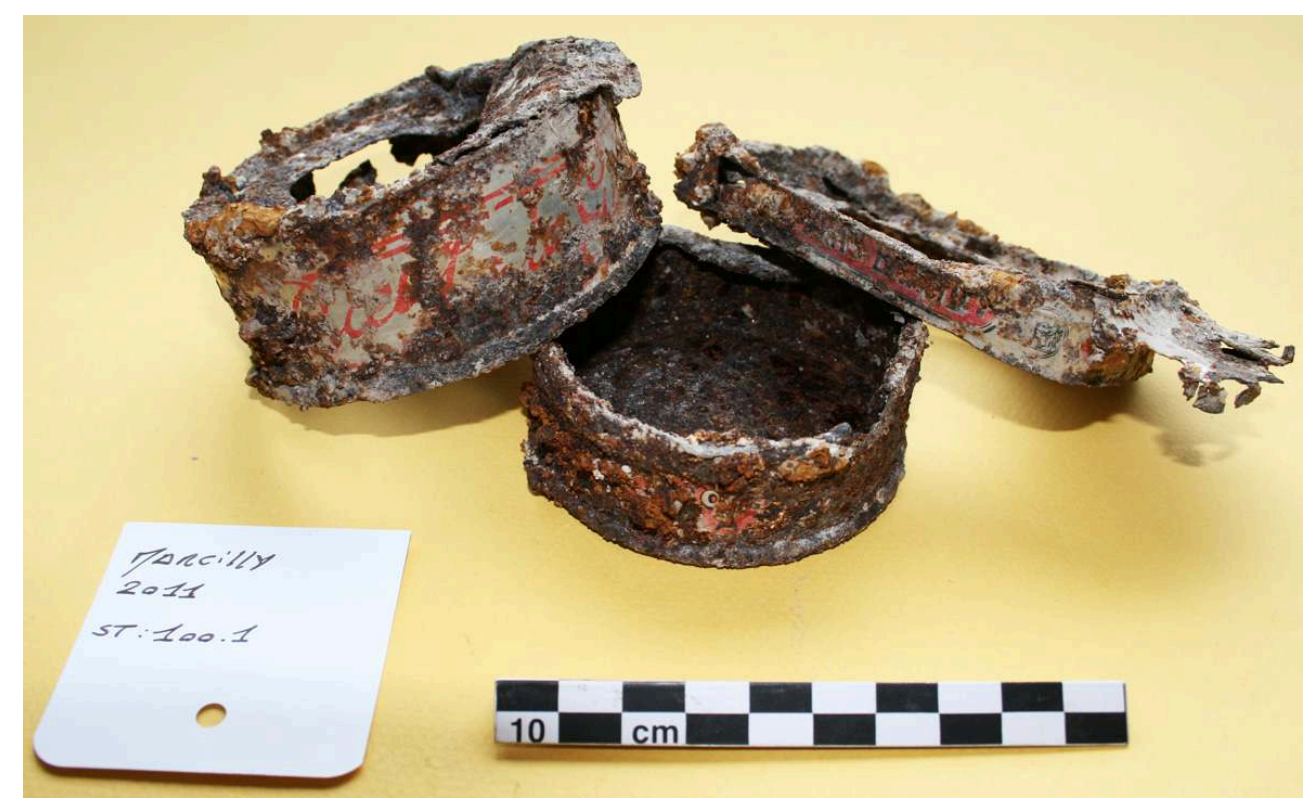

Sondage 101 : échantillon d'un lot important de boîtes de conserve mises au jour dans la fosse UF. 100-1. Les inscriptions ont partiellement résisté au temps. L'une des boîtes circulaires comporte la mention « Bœuf en Gelée » (appelé également « Singe » par les soldats) et la boîte de sardines (...) BRAS BAN (...) FRENCH ... ?

Phot. Devevey, Frédéric. (C) Frédéric Devevey.

En règle générale, les boittes de conserve de « dotations militaires » ne contenaient que $\mathrm{du}$ bœuf en sauce ou des sardines (ce qui est précisément le cas des échantillons découverts à Marcilly-sur-Tille). L'aspect des boîtes et leurs inscriptions ne se différenciaient pas, le plus souvent, des modèles destinés à la clientèle civile. L'une des boîtes de sardines trouvée à Marcilly-sur-Tille possède une inscription bilingue (français-anglais). À ces dernières venaient parfois s'ajouter d'autres aliments en boîte qui provenaient des apports civils (colis, foyer, boutiques...). L'arrivée des Américains et de leurs conserves de lait et de fruits donnera l'occasion d'échanges de nourriture (et de boisson !...) entre les alliés.

\section{Les éléments ferroviaires}

(fig. 25, 26, 27, 28, 29, 30) 
Figure 25

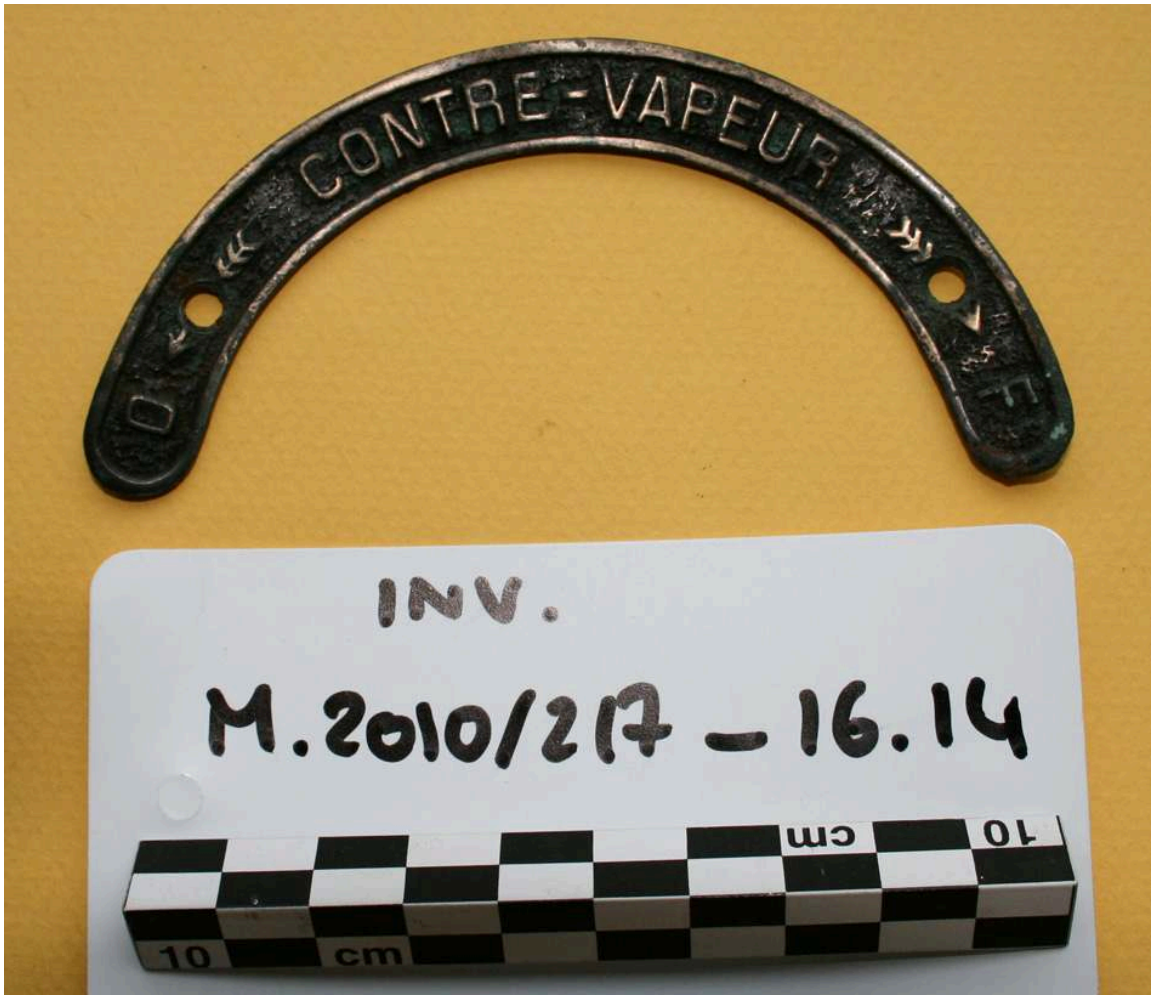

Élément de tableau de commande de machine à vapeur de type « DECAUVILLE ». Phot. Devevey, Frédéric. (c) Frédéric Devevey.

Figure 26

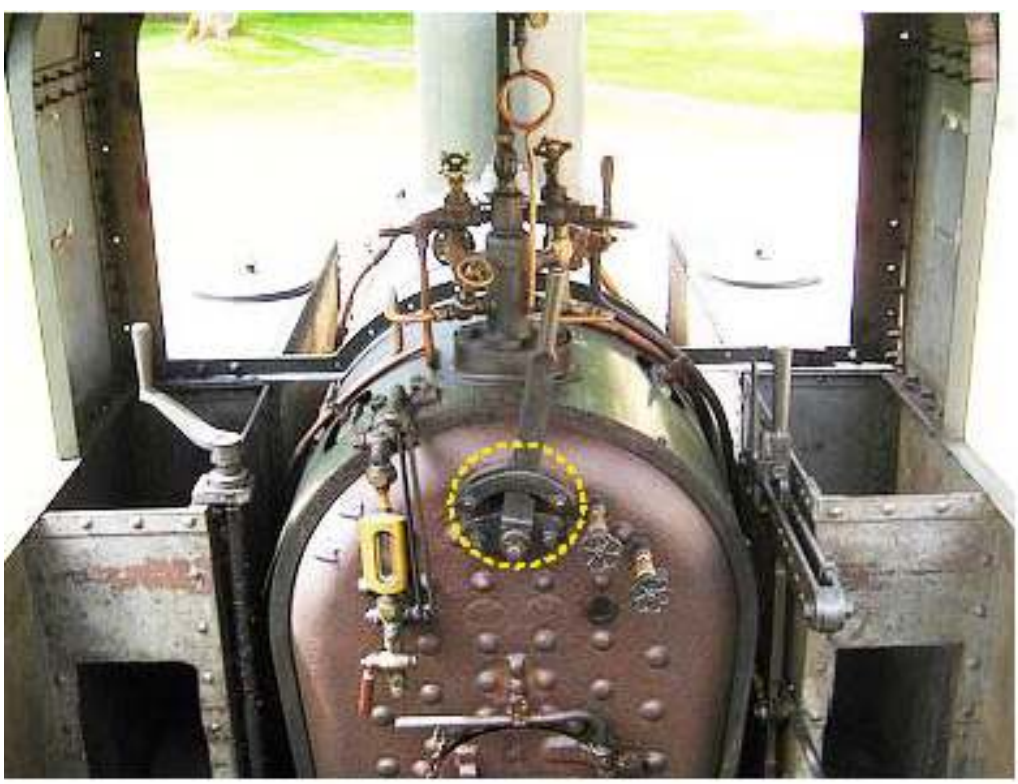

Localisation de l'objet sur une machine « Decauville » similaire (musée du Rail, Mulhouse). Phot. Devevey, Frédéric. (c) Frédéric Devevey. 
Figure 27

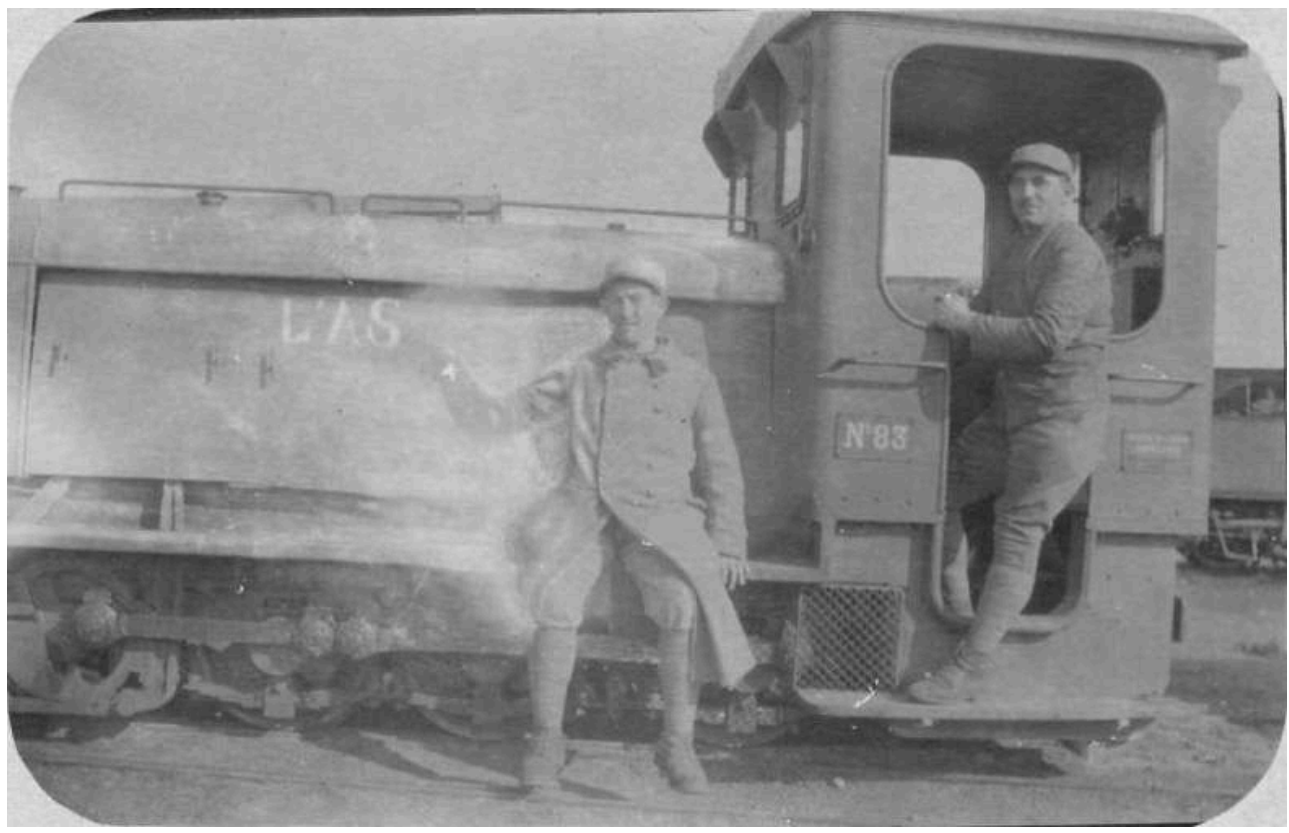

Exemple de locomotive de type «Decauville » utilisée dans les gares régulatrices durant la Première Guerre mondiale. (Sources : Service historique des Armées). La largeur d'une voie « Decauville » était de $0,60 \mathrm{~m}$.

Phot. Devevey, Frédéric. (c) Frédéric Devevey.

Figure 28

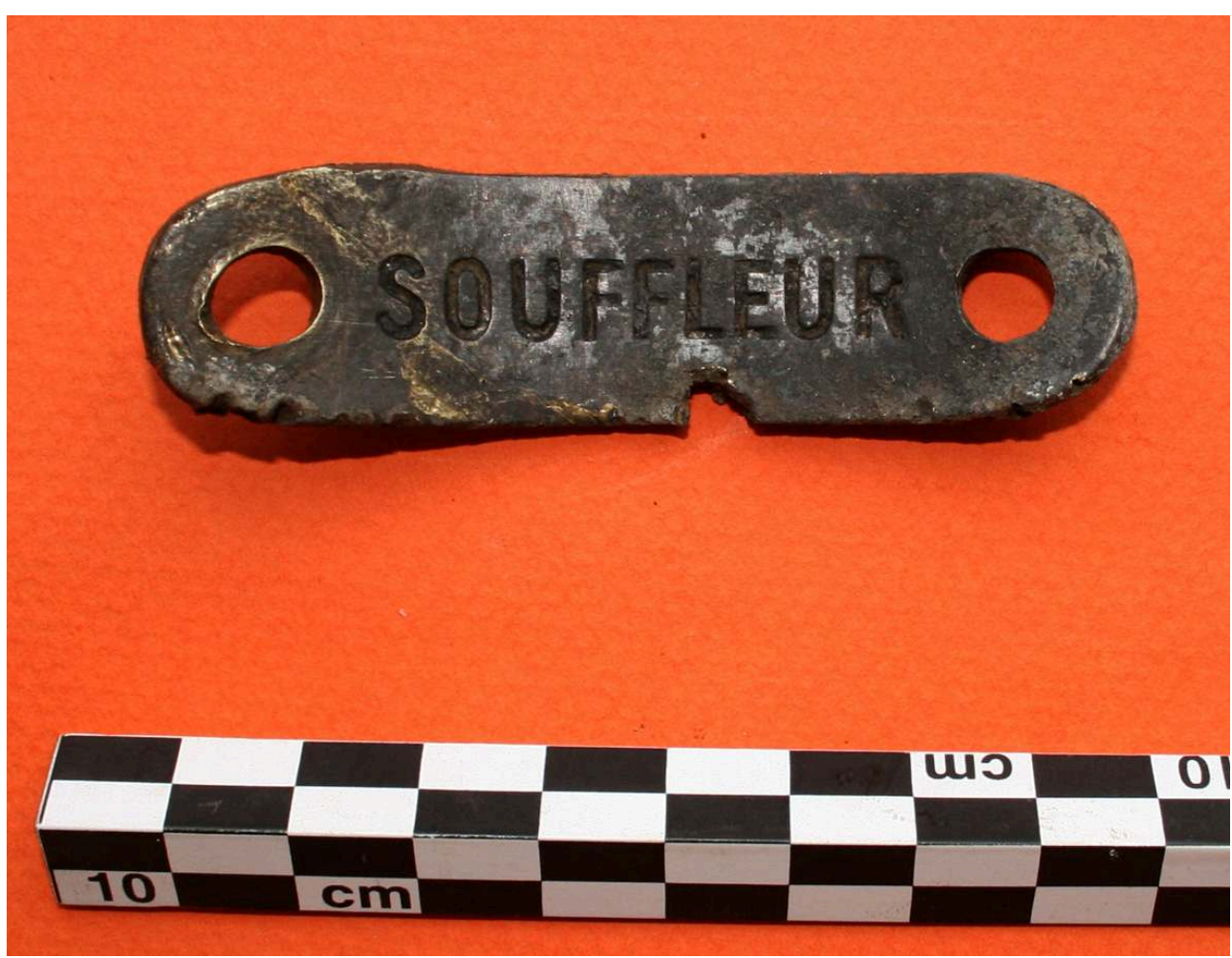

Sondage 68 : plaque de tableau de commande « souffleur ». À l'arrêt, la mise en marche du "souffleur » permettait de remplacer les gaz d'échappement pour entretenir le feu dans le foyer de la locomotive et laisser la machine sous pression.

Phot. Devevey, Frédéric. (c) Frédéric Devevey. 
Figure 29

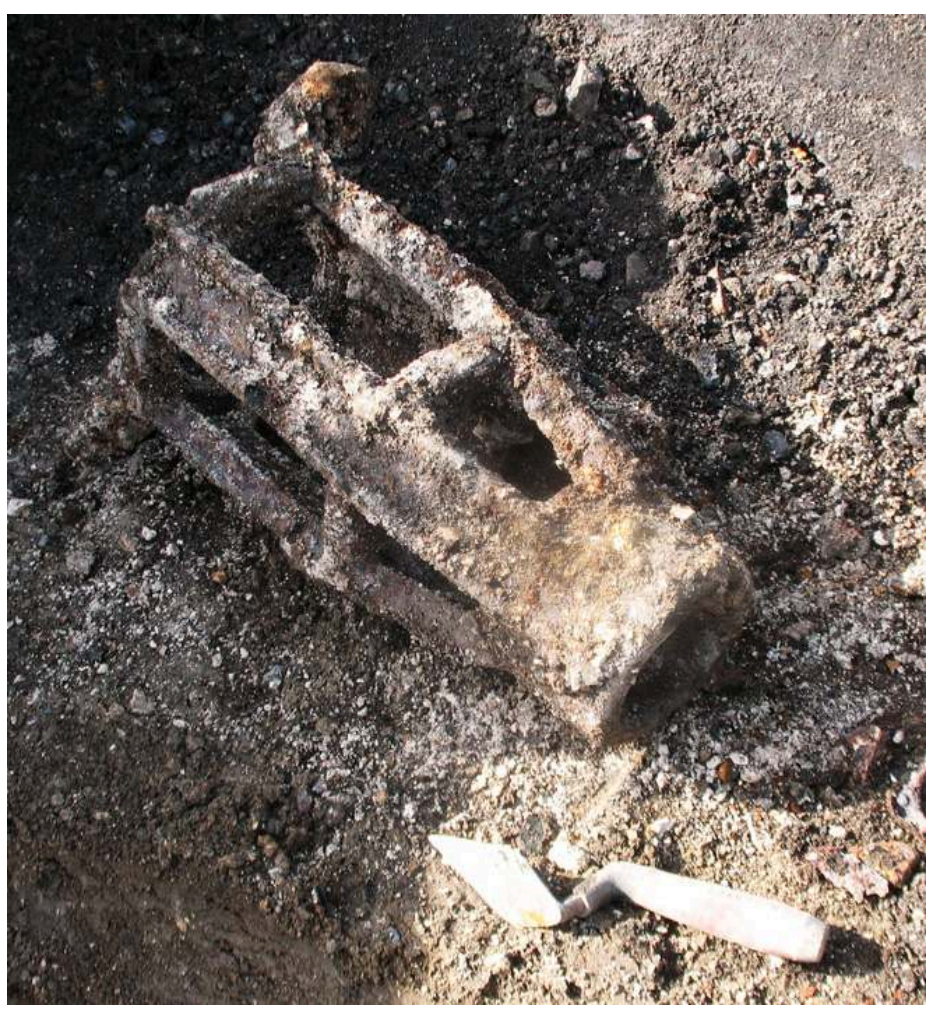

Sondage 5 : gaine de tampon de locomotive ou de wagon.

Phot. Devevey, Frédéric. (C) Frédéric Devevey. 
Figure 30
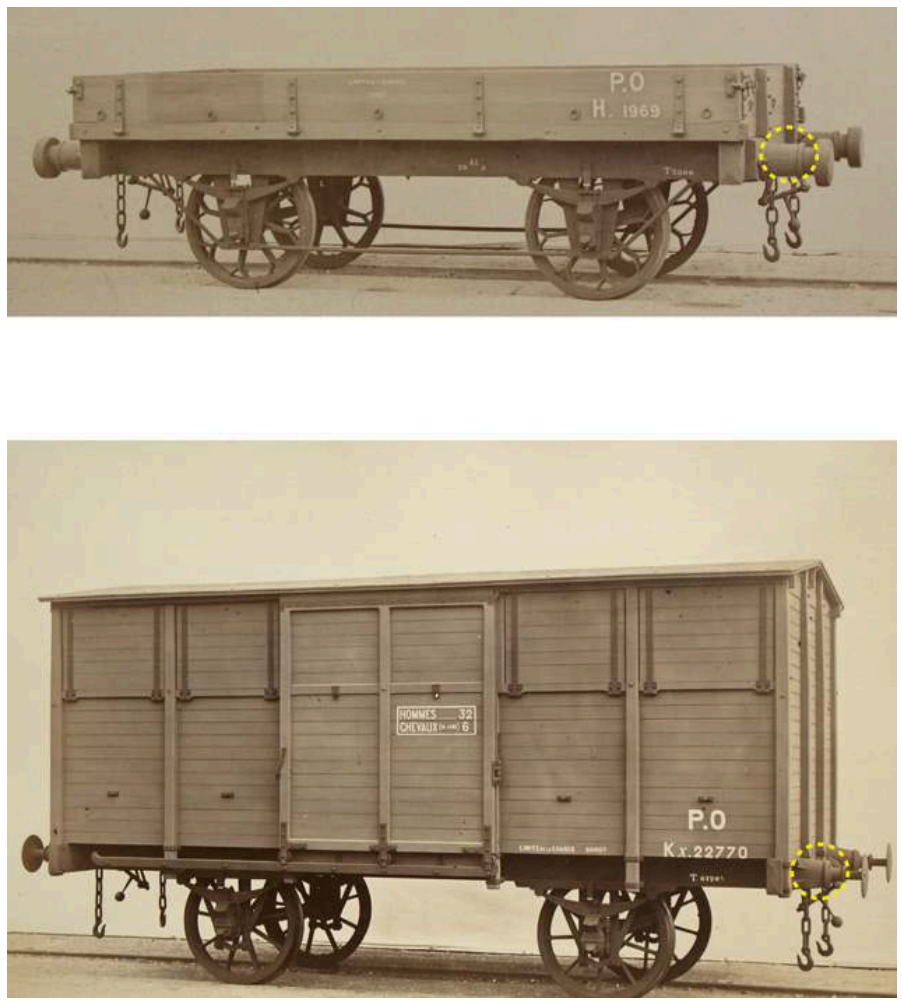

Localisation d'une pièce similaire sur deux wagons militaires Mdle. 1886.

Phot. Devevey, Frédéric. (c) Frédéric Devevey.

\section{Les militaria}

Bien que située sur une gare régulatrice militaire, le mobilier associé aux militaria reste modeste en quantité, dans la mesure où les cantonnements français et surtout américain se situent un peu plus au nord, sur la commune d'Is-sur-Tille. Cependant, quelques éléments ont été mis au jour lors de l'opération de diagnostic. Paradoxalement, le matériel américain y est représenté, preuve que la limite nord de l'opération correspond plus au moins à la «frontière » entre les gares régulatrices américaine et française (fig. 31 à 41). 
Figure 31

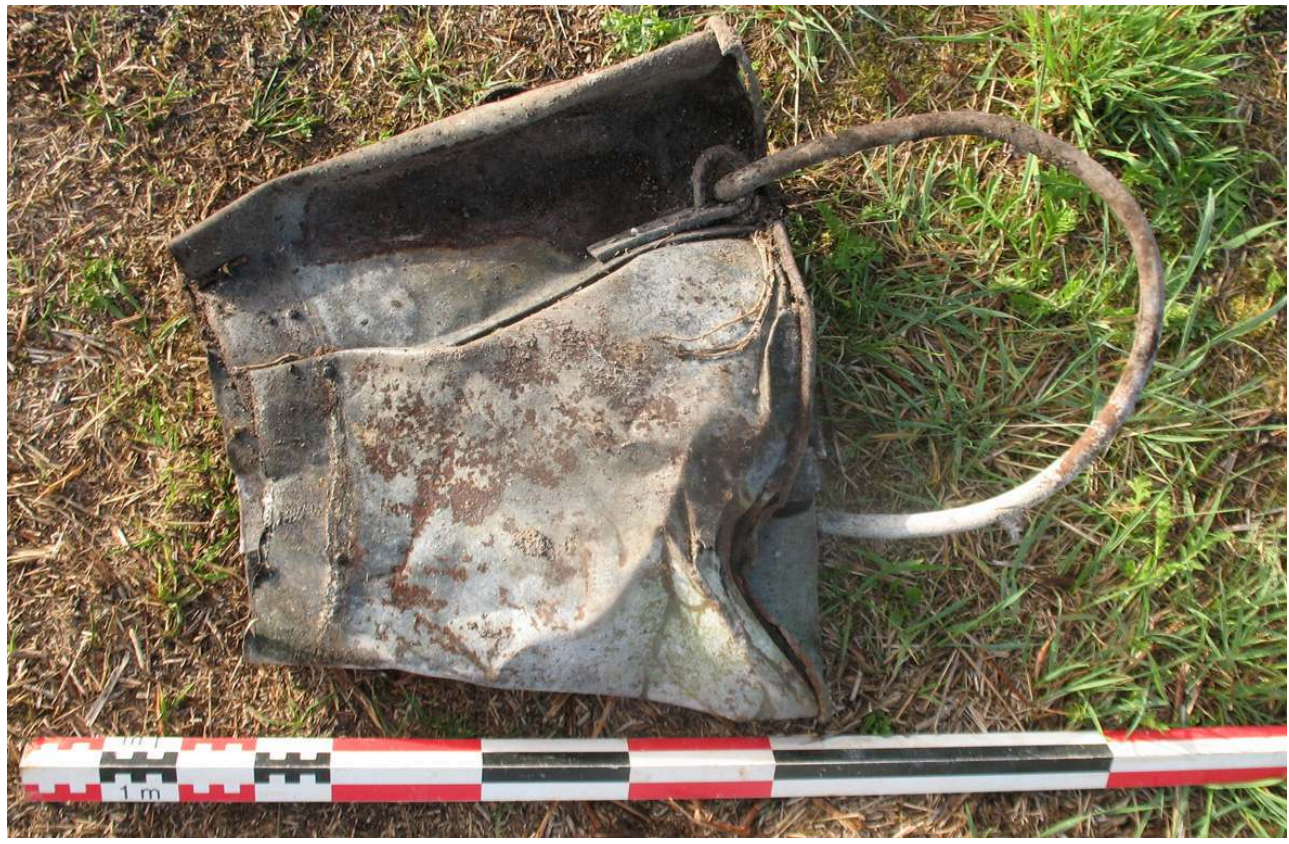

Seau indéterminé en zinc, marqué « Bullas 1917 » (trouvaille de surface).

Phot. Devevey, Frédéric. (c) Frédéric Devevey.

Figure 32

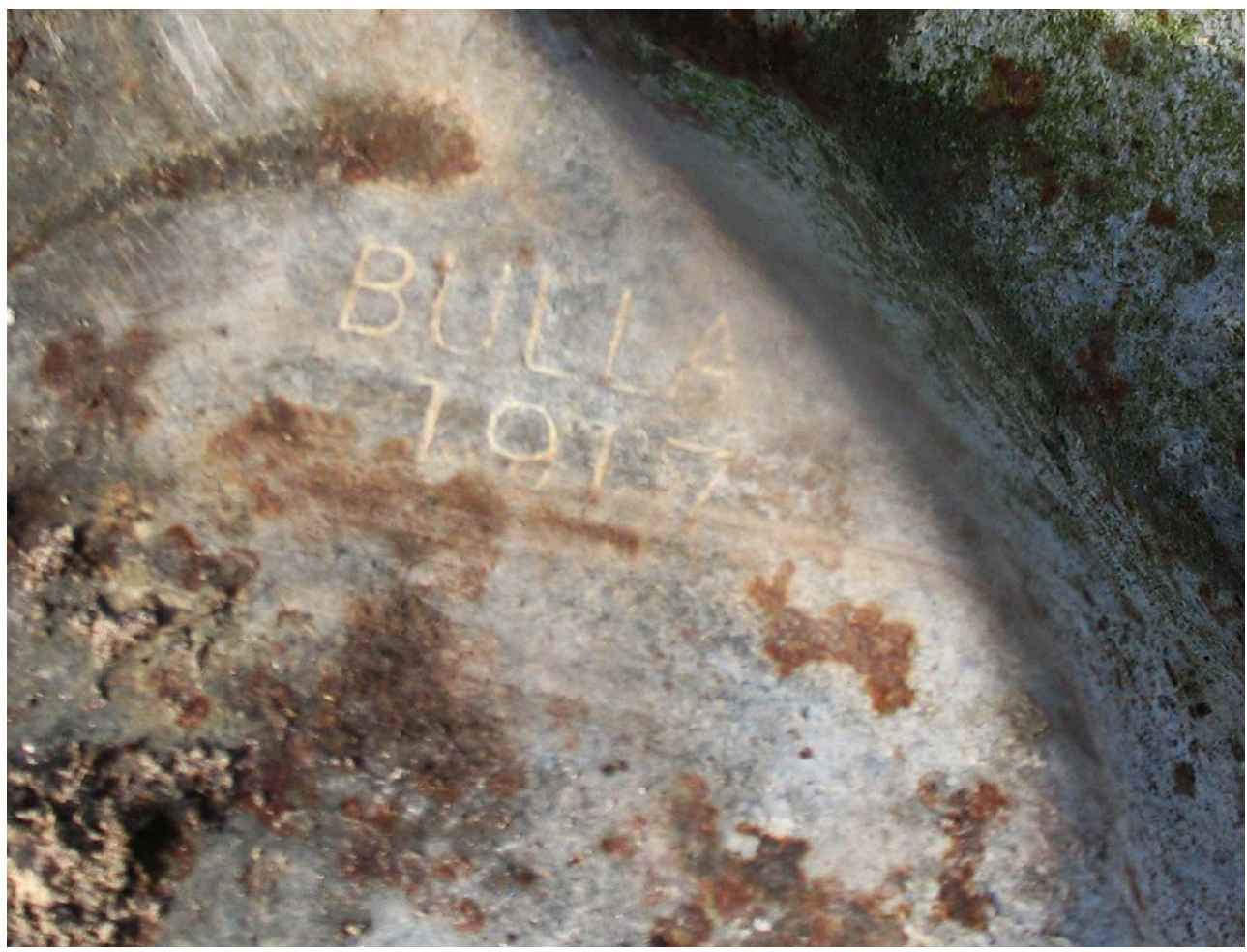

Détail du marquage «BULLAS 1917 ». L'inscription d'une date de fabrication laisse penser à une éventuelle origine militaire et américaine de cet objet.

Phot. Devevey, Frédéric. (c) Frédéric Devevey. 
Figure 33

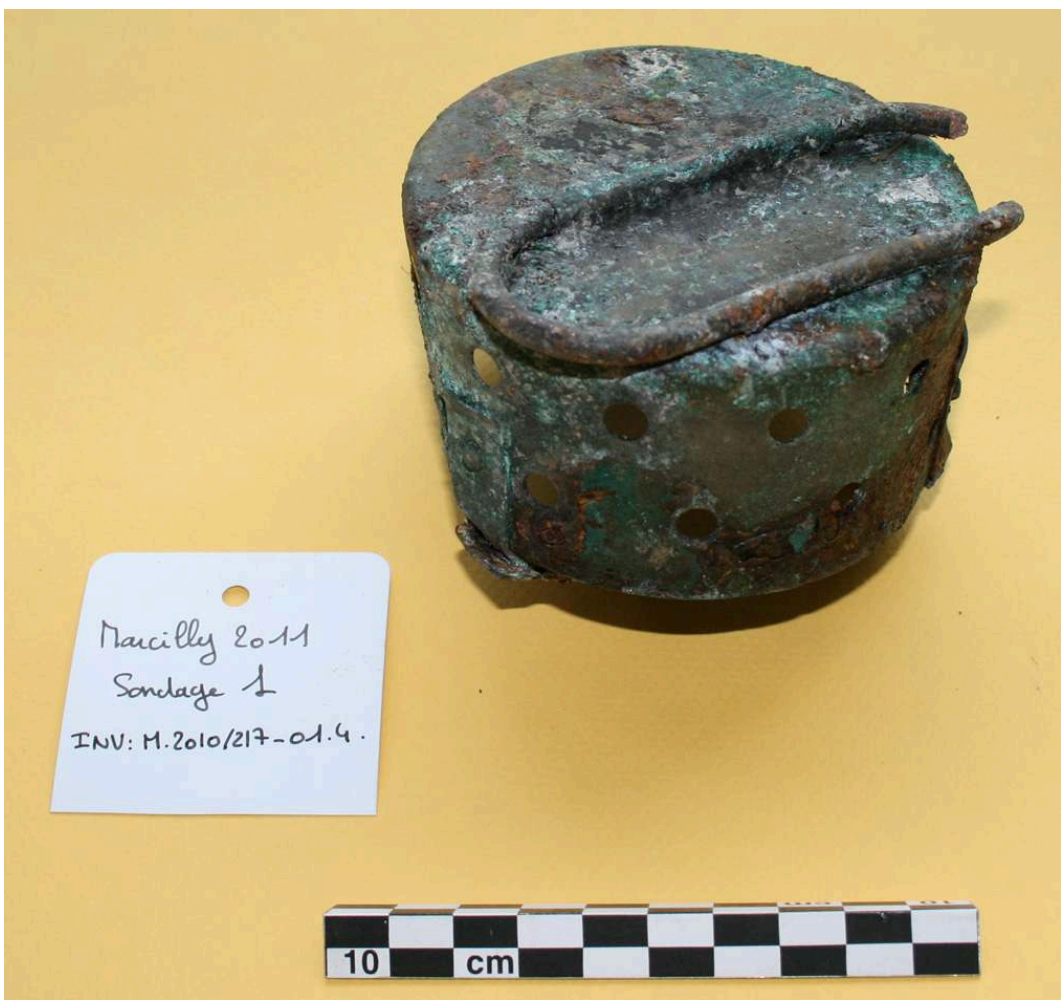

Sondage 1 : partie supérieure d'une lanterne portative (France ?).

Phot. Devevey, Frédéric. (c) Frédéric Devevey.

\section{Figure 34}

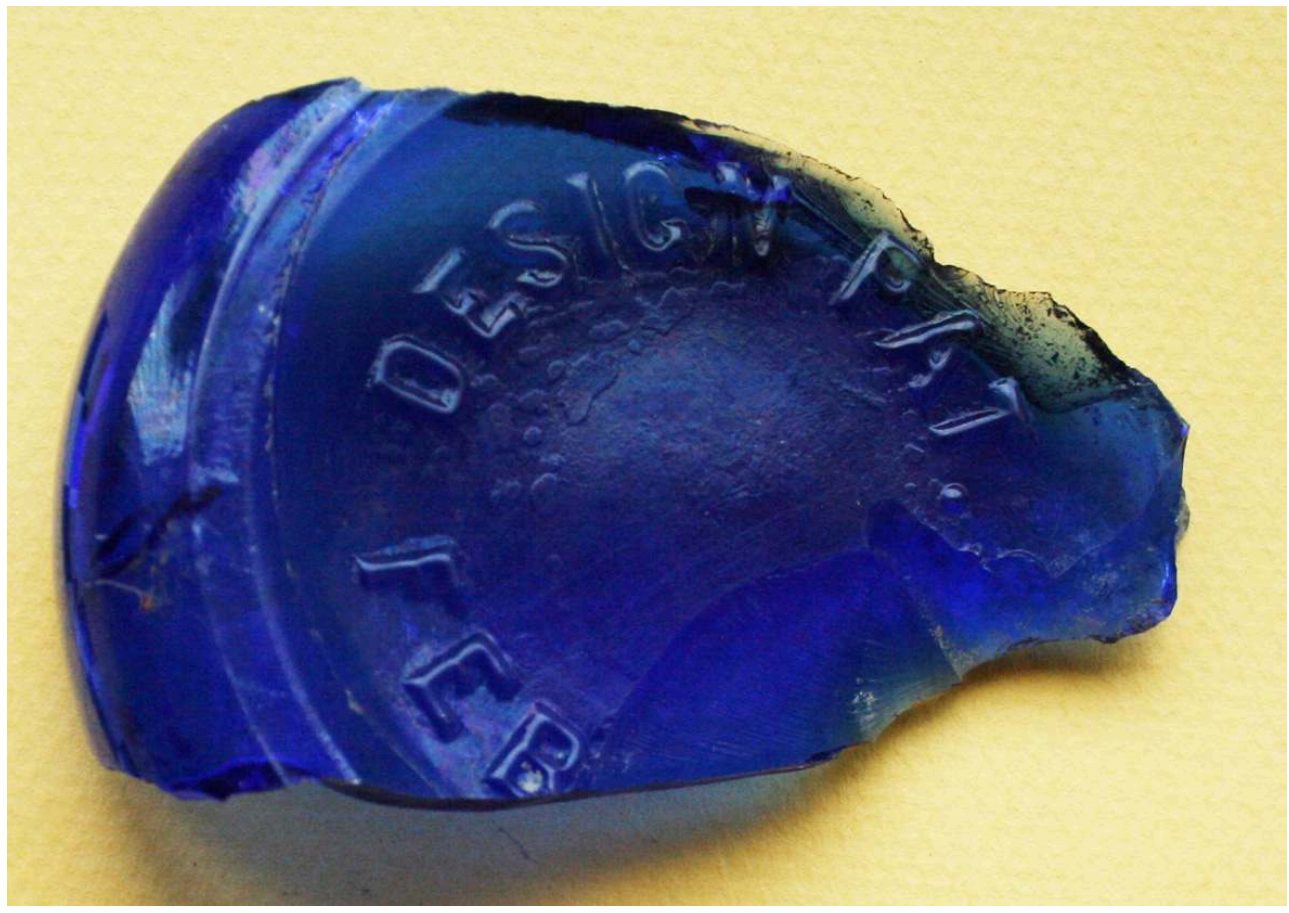

Sondage 1 : fond de récipient indéterminé en verre. La mention «DESIGN PAT. FEB(...) » lui confère sans conteste une origine militaire anglo-saxonne.

Phot. Devevey, Frédéric. (C) Frédéric Devevey. 


\section{Figure 35}

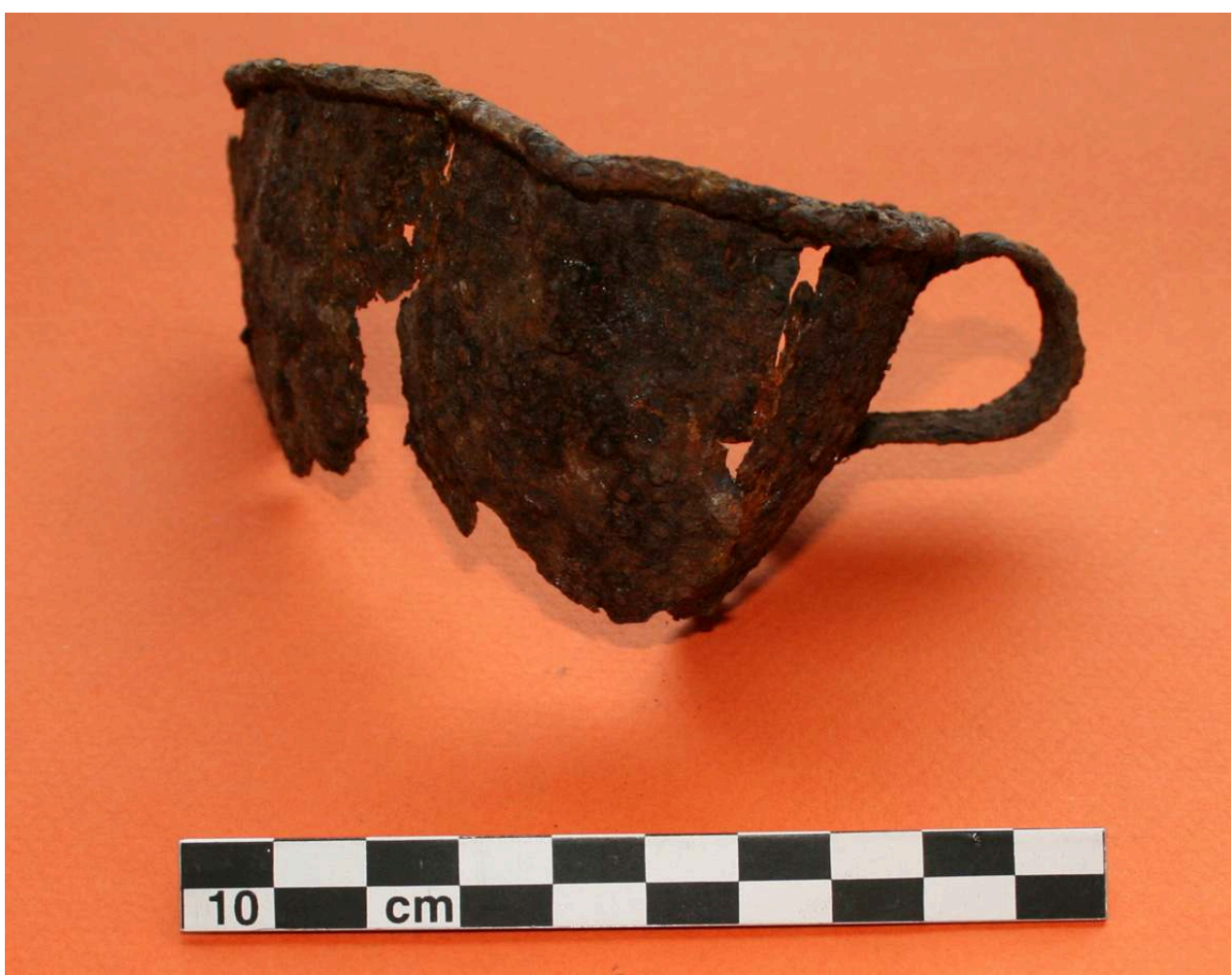

Sondage 68 : quart réglementaire en dotation dans l'armée française ou américaine.

Phot. Devevey, Frédéric. (C) Frédéric Devevey.

\section{Figure 36}
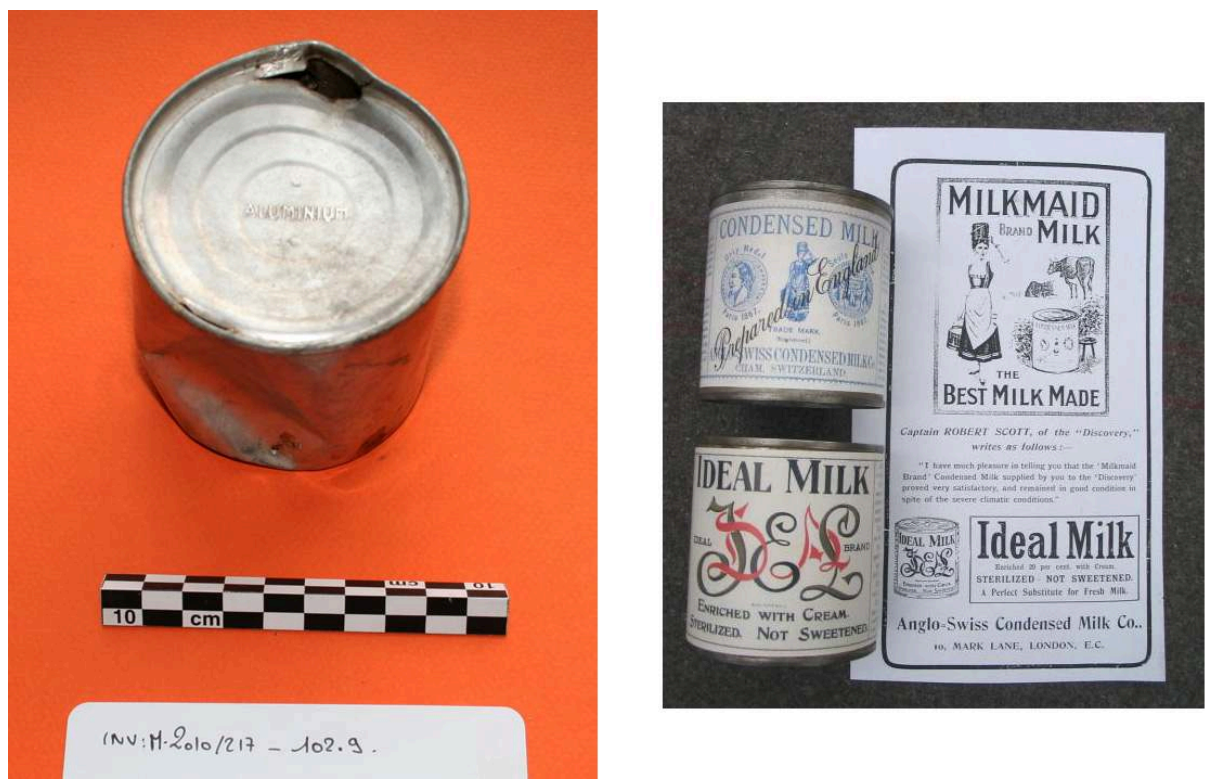

Sondage 102 (UF.102-9) : boîte de lait en aluminium (étiquette en papier disparue). Modèle américain Patern 1918. Les mentions « aluminium » présentes sur la partie supérieure et « alu » sur la partie inférieure devaient permettre au soldat d'identifier ce métal (rare et nouveau) afin qu'il puisse être recyclé. Une grande partie de ces rations étaient d'origine civile.

Phot. Devevey, Frédéric. (c) Frédéric Devevey. 
Figure 37
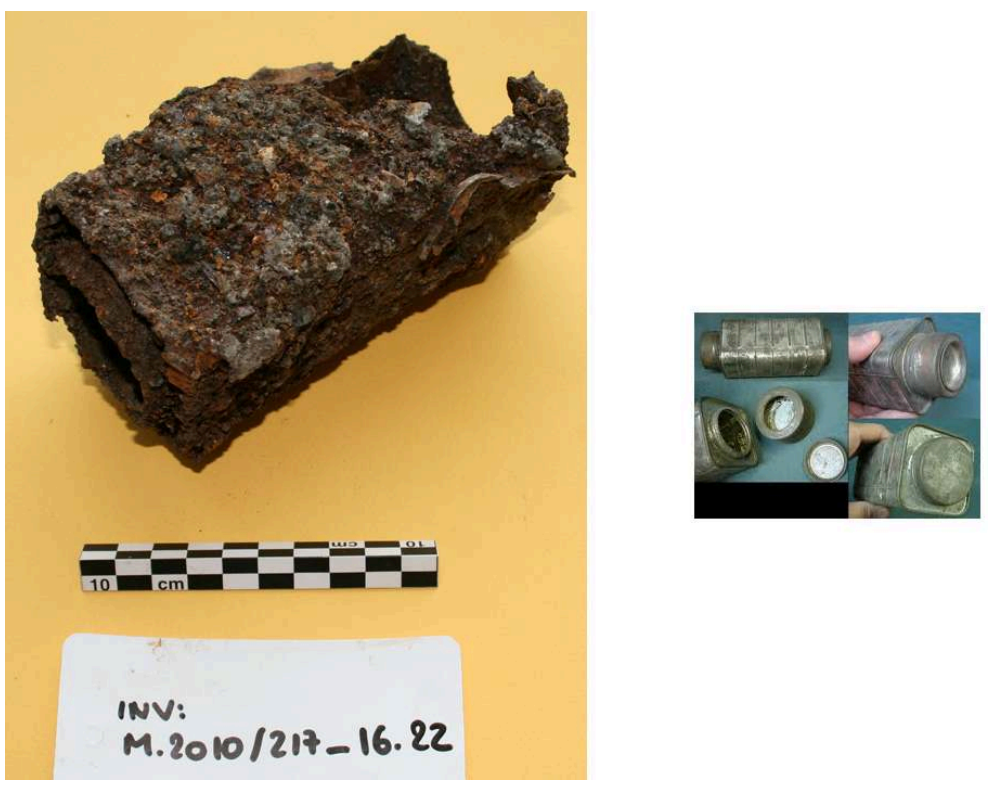

Sondage 16 : « célèbre » boîte à condiments en dotation générale dans l'armée américaine. Cet objet est particulièrement reconnaissable grâce à ses deux compartiments distincts (coll. GCM-1944).

Phot. Devevey, Frédéric. (c) Frédéric Devevey.

Figure 38

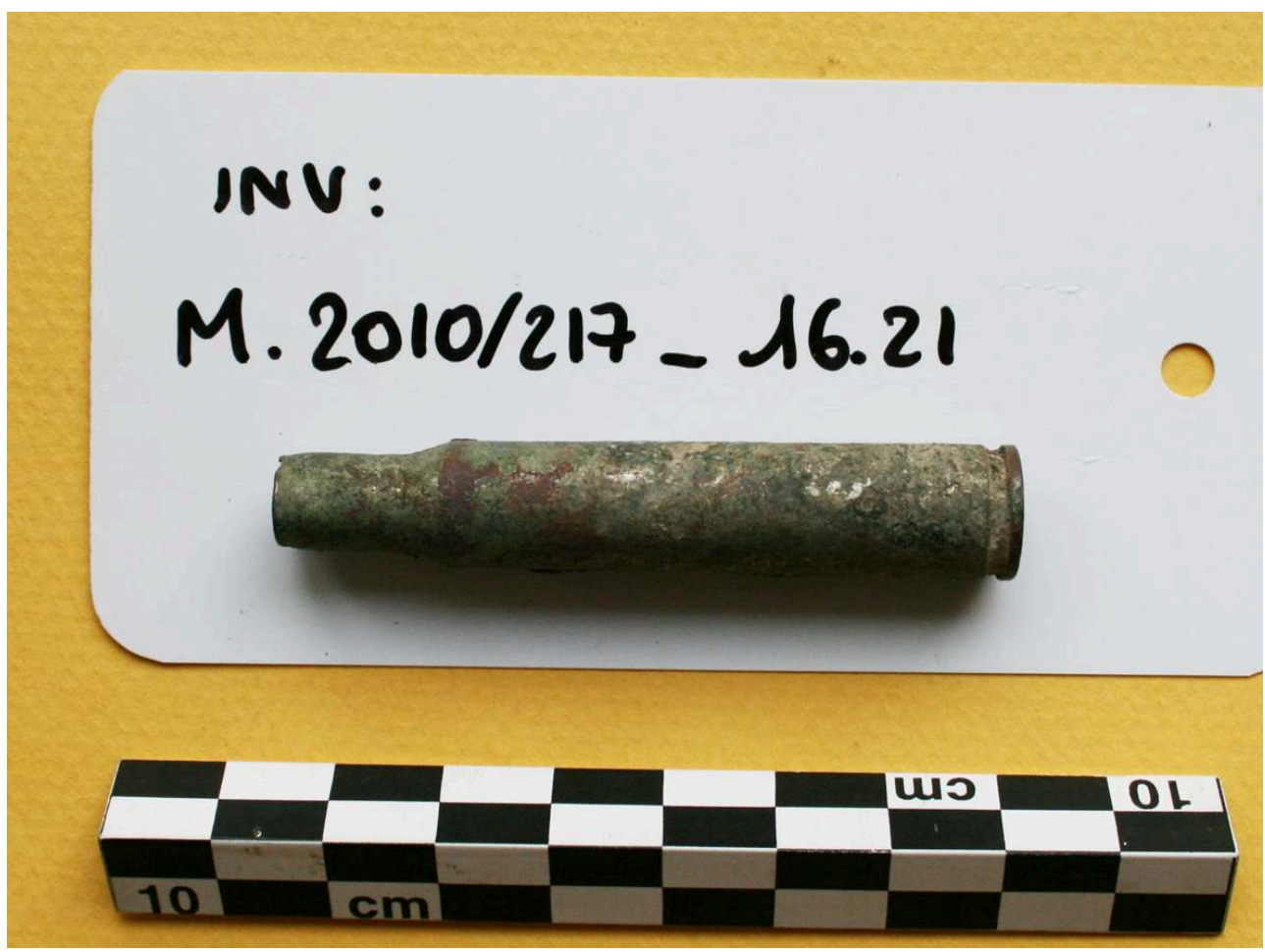

Sondage 16: douille américaine de calibre 30.06 qui équipait les fusils américains « Springfield». Phot. Devevey, Frédéric. (c) Frédéric Devevey. 
Figure 39

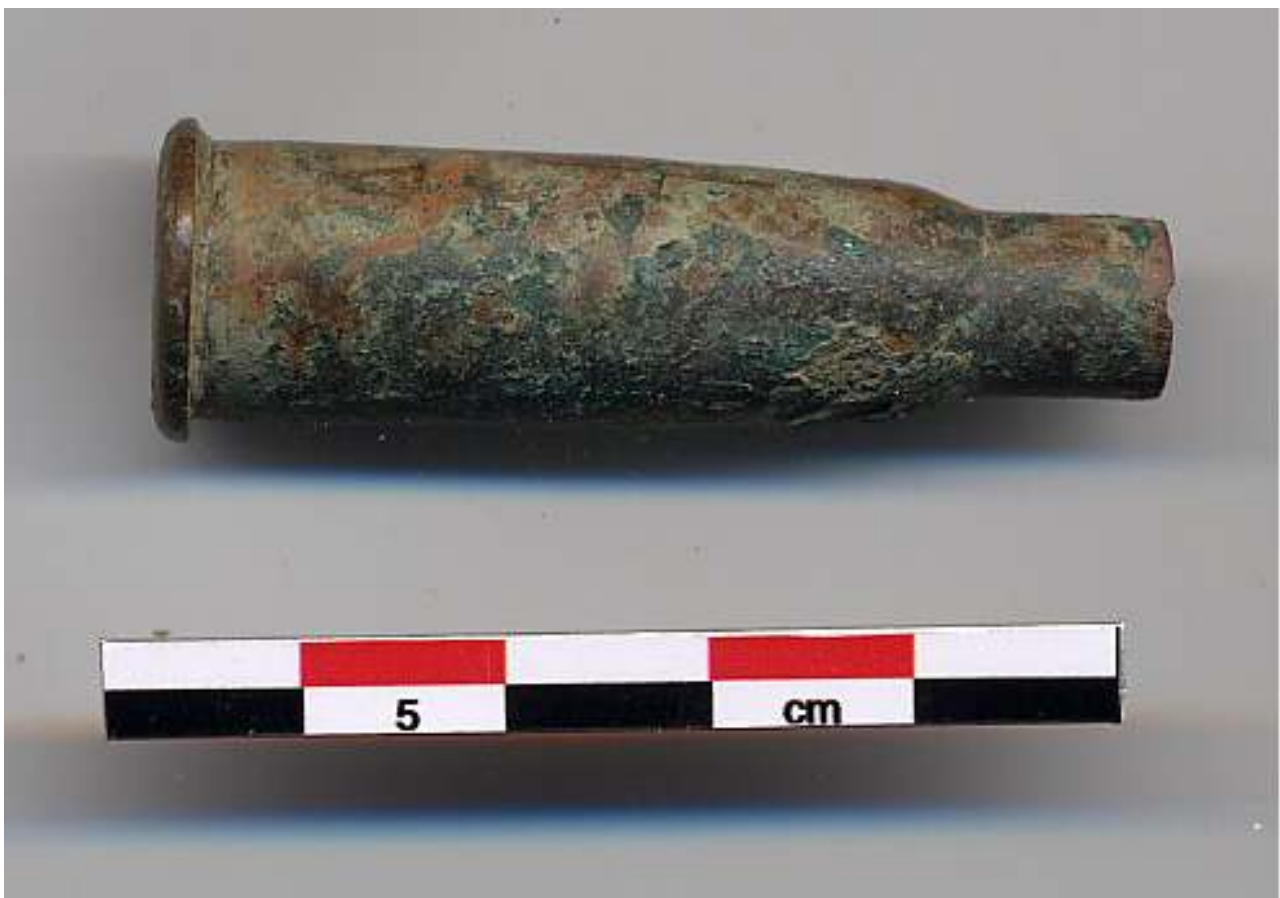

Sondage 111 : douille de calibre 8 mm utilisée pour les fusils français Lebel, modèle 1886. Phot. Devevey, Frédéric. (c) Frédéric Devevey.

Figure 40

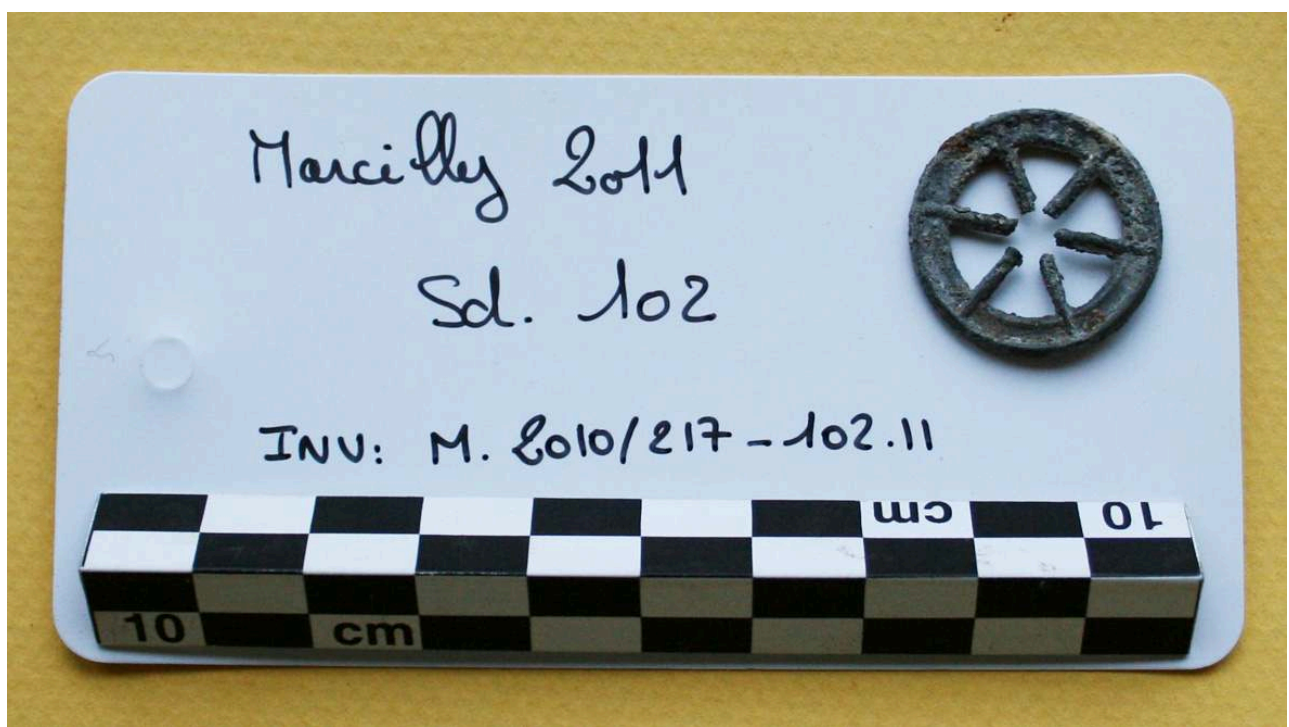

Sondage 102 : élément d'insigne métallique de spécialiste?

Phot. Devevey, Frédéric. (C) Frédéric DEVEver. 
Figure 41
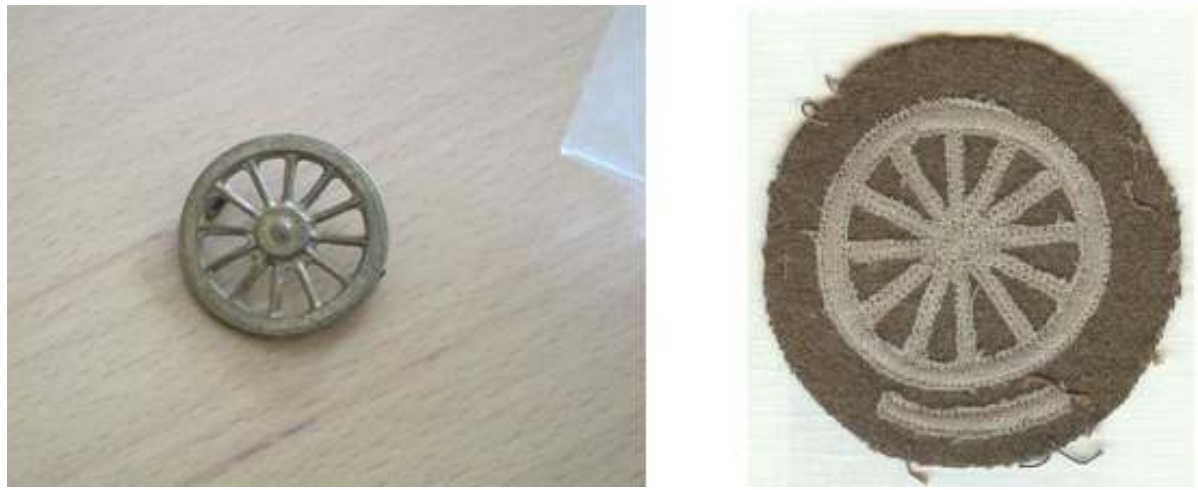

Insignes de l'armée américaine, en métal (officier) ou tissu (sous-officier) de « driver ». Plusieurs modèles ont été produits durant le conflit (source GCM.1944).

Phot. Devevey, Frédéric. @ Frédéric Devevey.

Ce fragment d'insigne de spécialiste pourrait appartenir à l'armée américaine, bien que le nombre de rayons soit supérieur à celui de l'objet trouvé lors de l'opération ${ }^{7}$. Il s'agirait alors d'un attribut de chauffeur, "driver ", de l'armée américaine. Toutefois, ce pourrait être également un insigne d'officier français de section des chemins de fer de campagne ou du régiment des chemins de fer ( $5^{\mathrm{e}}$ génie), bien que les modèles connus soient principalement en tissu ou brodés. Enfin, après l'armistice de 1918, la compagnie de chemins de fer Alsace-Lorraine (A.L.) utilisa ce genre d'insigne. On peut penser, enfin, à un fragment d'insigne britannique de l'artillerie (fig. 42, 43).

Figure 42
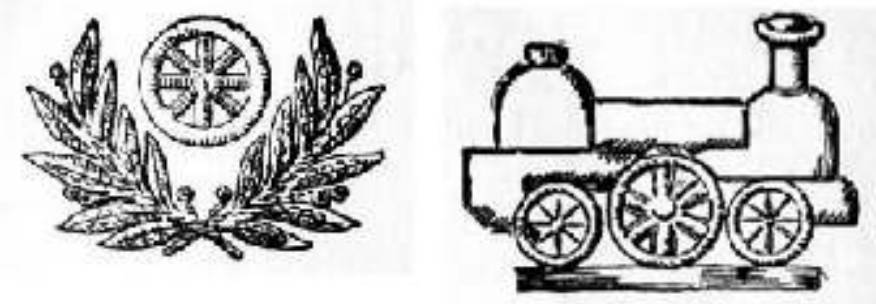

Attributs de vareuses de l'armée française (5e génie du train) en 1914-1918. Le modèle en tissu brodé était porté par les sous-officiers. Des versions (plus rares) en métal étaient destinées aux officiers, plus particulièrement dans les premiers temps du conflit. Enfin, la roue pourrait également avoir appartenu à un insigne d'artilleur.

Phot. Devevey, Frédéric. (c) Frédéric Devevey. 


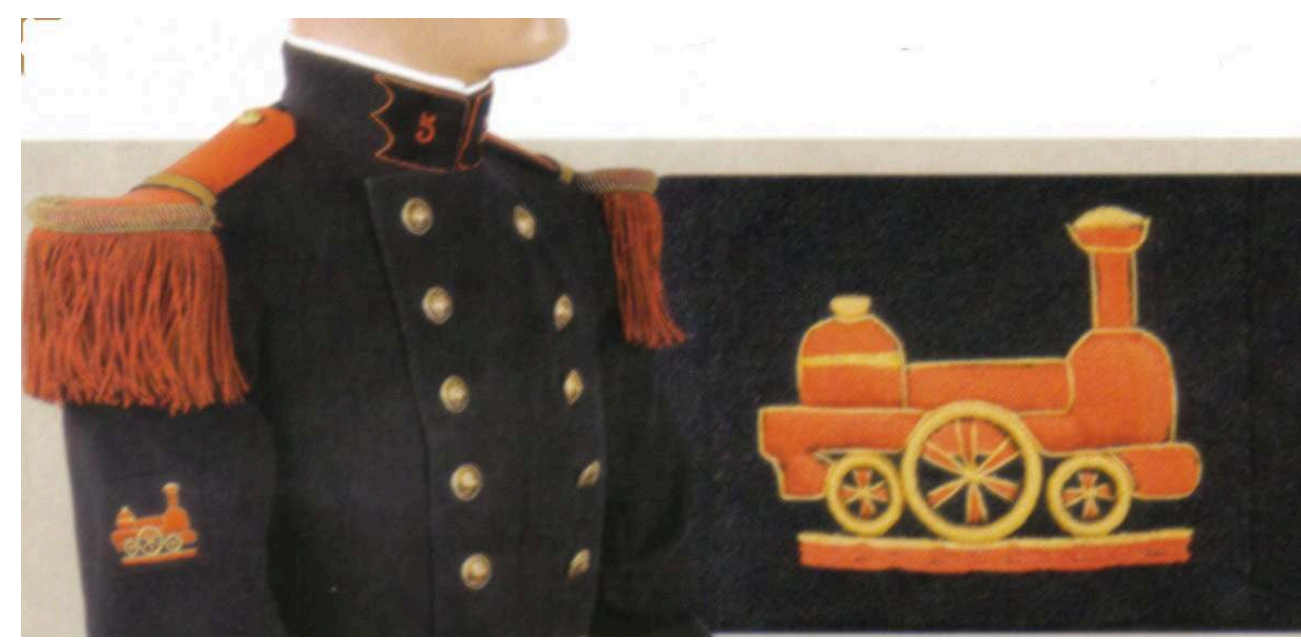

Attributs de vareuses de l'armée française (5e génie du train) en 1914-1918. Le modèle en tissu brodé était porté par les sous-officiers. Des versions (plus rares) en métal étaient destinées aux officiers, plus particulièrement dans les premiers temps du conflit. Enfin, la roue pourrait également avoir appartenu à un insigne d'artilleur.

Phot. Devevey, Frédéric. (C) Frédéric Devevey.

\section{Conclusion}

Les résultats obtenus lors de l'opération de diagnostic archéologique de Marcilly-surTille concernent exclusivement la première moitié $\mathrm{du} \mathrm{xx}^{\mathrm{e}}$ siècle et plus particulièrement la période de la Première Guerre mondiale.

Les vestiges et mobiliers mis au jour sont associés directement à la « gare régulatrice française », bien que la partie nord de l'emprise semble légèrement empiéter sur la limite sud du vaste camp américain mis en place dès juillet 1917.

Il est à noter que la prescription de fouilles archéologiques sur ce genre de site reste une première et mérite d'être soulignée. Les travaux d'Yves Desfossés, Alain Jacques ou Michaël Landolt (entre autres) ont permis la reconnaissance d'une discipline jusqu'alors délaissée, voire méprisée par la profession et qui ne trouvait d'attrait qu'auprès des collectionneurs et historiens.

L'opération de Marcilly-sur-Tille a permis de récolter diverses informations qu'une fouille pourrait affiner tant sur l'identification réelle des structures mises au jour, l'organisation générale de la gare régulatrice française puis de sa « connexion » avec le camp américain.

Le mobilier découvert permettrait de mettre en place une réflexion sur la logistique de l'approvisionnement depuis "l'arrière", que ce soit pour les troupes stationnées à Marcilly-sur-Tille ou pour celles envoyées sur le front. En effet, certaines structures ou secteurs du site livrent une très grande quantité de matériel, objets destinés à une consommation locale mais aussi peut-être objets en transit, abandonnés sur place (chute de caisses par exemple).

50 Depuis quelques années, grâce notamment aux travaux effectués par M. Landolt (PAIR, UMR 7044), une nouvelle problématique de recherches s'est développée sur le quotidien du combattant et plus particulièrement sur son alimentation. D'abord axées 
sur les soldats allemands, les études se sont à présent étendues à tous les belligérants présents en France et le long des frontières du Nord et de l'Est. Le site de Marcilly-surTille / Is-sur-Tille offre donc une excellente opportunité d'étude de l'approvisionnement, en troupes comme en matériel, pour l'armée française puis américaine.

Ce sujet n'a jamais été traité en Bourgogne en raison tout d'abord de l'absence de ligne de front ou de zones de combats relatives à la Première Guerre mondiale, mais également à cause d'une (supposée) bonne connaissance de cette période. L'étude des conditions de vie au front et au repos reste en fait parcellaire et anecdotique, face à l'histoire militaire ou diplomatique. L'étude des objets liés aux gares régulatrices françaises et américaines mérite pourtant une attention particulière car ils contiennent une quantité d'informations encore inexploitées.

En arrière du front, l'emplacement des dépotoirs est-il défini et le remplissage peut-il révéler une gestion raisonnée, voire une affectation par unité ou par type de matériaux ? Les sources locales (orales et écrites) décrivent des « fosses » qui pouvaient parfois atteindre plusieurs mètres cubes (notamment au départ des Américains, en 1919).

53 Le site "du camp français et américain ", s'il répond à ces critères, semble également présenter des spécificités liées aux zones d'extraction des graviers de la Tille, comblées par les déchets issus de la gare, phénomène qui semble reconnu pour l'été 1914 (mobilisation générale) et l'été 1917 (arrivée des Américains à Is-sur-Tille).

54 Le traitement des déchets sur la gare régulatrice est mal connu, si ce n'est que la priorité était accordée au comblement des zones d'extraction, en vue d'aplanir le terrain pour ensuite poser les voies.

\section{Annexes historiques}

\section{L'organisation des chemins de fer en 1914-1918}

Pour organiser le transport, la construction et l'exploitation de lignes militaires, le ministère de la Guerre avait un service dénommé direction des Chemins de fer de campagne (D.C.F.C.) comprenant des compagnies de sapeurs de chemins de fer fournies par le $5^{\mathrm{e}}$ régiment du génie et de sections de chemins de fer de campagne.

Les sections de chemins de fer de campagne ou sections techniques d'ouvriers de chemins de fer de campagne étaient des unités militaires dont l'organisation était prévue bien avant le commencement des hostilités. Elles étaient chargées en temps de guerre, avec les sapeurs de chemins de fer du $5^{\mathrm{e}} \mathrm{RG}$, de la construction, de la réparation et de l'exploitation des voies ferrées dont le service n'était alors plus assuré par les compagnies nationales et locales.

57 Leur personnel, recruté parmi les ingénieurs, employés et ouvriers au service des grandes compagnies et du réseau de l'État, soit volontaires, soit assujettis au service militaire par la loi de recrutement, était réparti en dix sections formées de la manière suivante :

- $1^{\mathrm{e}}$ et $2^{\mathrm{e}}:$ Paris-Lyon-Méditerranée

- $3^{\mathrm{e}}$ : Paris-Orléans

- $4^{\text {e }}$ et $9^{\mathrm{e}}$ : État 
$\cdot 5^{\mathrm{e}}:$ Nord

$\cdot 6^{\mathrm{e}}:$ Est

$\cdot 7^{\mathrm{e}}:$ Midi

- $8^{\mathrm{e}}$ : Est, État et Nord

$\cdot 10^{\mathrm{e}}$ : lignes secondaires.

Il s'y ajoute, au commencement de 1917 , une $11^{\mathrm{e}}$ section fournie par le P.L.M., et, après l'armistice de 1918 , une $12^{e}$, constituée par tous les réseaux pour la direction et la surveillance du service en Alsace-Lorraine.

Chaque section comprenait un commandant avec les attributions de chef de corps, des fonctionnaires, employés et ouvriers, répartis entre un service central, les trois divisions du mouvement, de la voie et de la traction et un dépôt central commun.

列 pour la traction, blanc pour l'exploitation, jaune pour la voie et l'entretien. Pour résumer, le système fonctionnait comme de petites compagnies de chemins de fer pouvant exploiter de 100 à 200 kilomètres de voies, suivant l'intensité des transports.

6 décembre 1914: sapeurs du $1^{e r}$ bataillon de la $4^{e}$ compagnie du $5^{e}$ régiment du génie (unique régiment spécialisé dans les chemins de fer) ${ }^{8}$. Ce régiment fut chargé de la mise en place et de l'entretien des gares régulatrices et des voies ferrées menant aux différents fronts.

Avec les événements de la guerre 14-18, les activités de chaque section ont été redéployées sur l'ensemble de la ligne de front. Sur ces dix sections, sept ont été mobilisées en tout ou en partie durant le conflit. Celles qui ont fourni le plus gros effort sont la $3^{\mathrm{e}}$, la $7^{\mathrm{e}}$ et la $10^{\mathrm{e}}$. La $3^{\mathrm{e}}$ section, par exemple, mobilisée de mars 1916 à octobre 1919, a exploité la ligne de la Somme pendant les opérations de 1916 et participé, après le repli allemand de mars 1917, à la remise en état du réseau récupéré. La 10 ${ }^{e}$, mobilisée en novembre 1914, a exploité tous les réseaux de voie métrique utilisés pour les opérations militaires : chemin de fer belfortien, ligne de Lunéville à Einville, réseau meusien, où elle a accompli un remarquable effort pendant la bataille de Verdun, chemins de fer de la banlieue de Reims, réseaux des Flandres. La gare régulatrice de Saint-Dizier expédia quotidiennement sur Verdun 21 trains de vivres, 7 de munitions, 9 de matériel, 2 de troupes, évacuant aussi 5 à 7 trains de blessés. Au total, du 21 février au $1^{\mathrm{er}}$ juin 1916, l'ensemble du trafic s'éleva à 119000 wagons. Des fractions de la $1^{\mathrm{e}}$ section ont été mobilisées du 20 avril 1916 au 15 avril 1919. La 6e section, partiellement mobilisée de mai 1915 à février 1919, a mis en service les lignes du réseau d'AlsaceLorraine reconquises au début de la campagne. La $9^{\mathrm{e}}$, partiellement mobilisée en 1915, a exécuté des travaux de voies dans le Nord. La $4^{\mathrm{e}}$ section a été mobilisée après l'armistice de 1918. Après l'armistice, le personnel des sections de chemins de fer de campagne participe à l'exploitation des réseaux d'Alsace-Lorraine, du Luxembourg et des pays rhénans. Le ministère de la Défense nationale a attribué une carte de combattant aux anciens cheminots des sections de chemins de fer de campagne. 


\section{BIBLIOGRAPHY}

ANTOINE, A., BAHAIN, J.-J., BERILLON, G. et ASGARI KHANEGHAH, A. « Tuf calcaire et séquence alluviale en contexte tectonique actif : la formation de Baliran (province du Mazandaran, Iran) ». Bulletin de l'Association française pour l'étude du quaternaire, 2006, Volume 17, n 4, p. 321-331.

CATTANEO,G., PASCAL, A., RAT,P., AMIOT, M. et JOLY, J. Notice explicative de la carte géologique d'Issur-Tille au 1/50 000. BRGM, 1978.

CLAIR, A., DORET, G. et PUISSEGUR, J.-J. « Un exemple de sédimentation quaternaire dans les vallées de moyenne importance en domaine paléarctique : étude stratigraphique et malacologique des alluvions de la Tille et de la Norges au N-E de Dijon (Côte-d'Or) ». Bulletin de l'Association française pour l'étude du quaternaire. 1972, volume 9, n², p. 101-124.

DESFOSSÉS, Y., JACQUES, A., PRILAUX, G. L'archéologie de la Grande Guerre. Paris : INRAP-Éditions Ouest-France, 2008.

Les gares régulatrices d'Is-sur-Tille, 1914-1918. Société d'Histoire Tille-Ignon (SHTI), septembre 2005.

JAUFFRET, D. « Ressources patrimoniales en eau souterraine de la Côte-d'Or : délimitation, caractéristiques et propositions pour leur préservation ». BRGM/RP-52156-RF, février 2003.

LANDOLT, M., DECKER, E., LEPROVOST, C., LESJEAN F. et PUTELAT, O., Aspach-Carspach Lerchenberg et Lerchenholz (Haut-Rhin) : découvertes archéologiques sur la première ligne de front allemande (1914-1918). Annuaire de la Société d'Histoire du Sundgau, 2009, p. 19-58.

Landolt et Lesjean 2009 : M. LANDOLT et F. LESJEAN, L'alimentation du soldat allemand sur les fronts d'Alsace et de Champagne à travers l'approche archéologique des dépotoirs de la Première Guerre Mondiale, Cahiers Alsaciens d'Archéologie d'Art et d'Histoire, LII, 2009, p. 139-159.

Llosa M. : 2008 : La conserve alimentaire au service du soldat - « Matériaux pour l'Histoire de notre temps » $n^{\circ} 91$, juillet-septembre 2008

Liens Internet

http://www.ecpad.fr/tag/train (Film de 1917 structuré en cinq parties, présentant un bilan en images, dressé par le général Joffre à l'intention du général Pershing et du peuple américain, sur les actions entreprises par la France " pour défendre la liberté ») - Images de gares régulatrices / trains.

http://www.ecpad.fr/les-petits-trains-de-la-grande-guerre-2

Pour illustrer l'importance du réseau ferroviaire militaire à voie de 0,60 $\mathrm{m}$ au cours du premier conflit mondial, un montage a été réalisé à partir d'extraits de films tournés entre 1915 et 1918 par les opérateurs de la section cinématographique de l'armée.

Ce montage d'archives présente les matériels du système mis au point par le colonel Péchot (bogies, locomotive Péchot-Bourdon, plate-forme d'artillerie modèle 1888 et ses dérivés, notamment l'affût Peigné-Canet) ainsi que les autres matériels réquisitionnés ou commandés par l'armée aux constructeurs français comme Decauville et Crochat, ou étrangers, tels Baldwin ou Kerr-Stuart. Les images montrent également la construction et l'entretien des réseaux par les hommes des deux régiments d'artillerie à pied qui en étaient chargés. Elles illustrent les différents types d'emprises (sur chaussée, en forêt, en tranchée, sous camouflage, voire en souterrain), ainsi que la vie quotidienne sur la voie de $0,60 \mathrm{~m}$, qui assurait la liaison entre les gares des lignes ferroviaires à voie normale et les abords immédiats du front : acheminement des 
munitions et des subsistances, transport des hommes et du matériel, entretien des locomotives, travail forestier et contribution au fonctionnement de l'artillerie.

http://fr.wikipedia.org/wiki/Cheval_dans_la_Premi\%C3\%A8re_Guerre_mondiale

Les chevaux durant la Première Guerre mondiale.

http://www.airdefenseartillery.com

Site historique de la défense antiaérienne américaine.

http://passionlocos.e-monsite.com/album-cat-3-250285.html

Site sur l'histoire des locomotives à vapeur.

\section{NOTES}

1. - De nos jours encore, la gare est injustement désignée « Gare d'Is-sur-Tille », bien qu'installée sur la commune de Marcilly-sur-Tille.

2. - Le lecteur pourra s'interroger sur le bien-fondé de creuser de vastes excavations pour les reboucher quasiment dans la foulée... Mais la nature même des rejets de locomotives ne se prête pas à une utilisation immédiate comme ballast pour asseoir des voies ferrées.

3. - Les gares régulatrices d'Is-sur-Tille, 1914-1918. SHTI, 2005.

4. - Département de la Meurthe-et-Moselle (Lorraine).

5. - D’après Émile Fournier, témoin des événements.

6. - La mention "Breveté S.G.D.G.» est une abréviation qui signifie «sans garantie du gouvernement». Cette mention dégageait l'État de toute responsabilité en cas de mauvais fonctionnement d'un dispositif breveté.

7. - Très souvent, les membres du personnel d'encadrement les plus fortunés commandaient des tenues civiles à des tailleurs.

8. - Régiment dissout en juin 2010,120 ans après sa création.

\section{ABSTRACTS}

Situated at the frontier between the departments of the Côte d'Or and the Haute-Marne, the Marcilly-sur-Tille railway station owes its existence to the East railway company and to the late nineteenth-century development of railway traffic on the line between Dijon and Neufchateau. The outbreak of war in 1914 was to give this station a new and vital role. From 2 August 1914, the station was comprised in the general plans for mobilisation and became a 'gare régulatrice de communication', a regulatory communications station, according to the military designation of the time. Following heritage regulations, an operation of archaeological diagnosis was carried out on the site in April 2011. This article presents the first findings of this archaeological operation, the first of its kind in the Burgundy region.

Implantée aux confins des départements de la Côte d'Or et de la Haute-Marne, la gare de Marcilly-sur-Tille doit en partie son existence à la Compagnie de l'Est et au développement du chemin de fer sur le tronçon Dijon-Neufchateau à la fin du XIX ${ }^{\mathrm{e}}$ siècle. Le déclenchement de la 
Première Guerre mondiale allait donner un nouveau (et essentiel) rôle à cette gare. En effet, cette dernière supporte sa pleine charge ferroviaire dès le 2 août 1914, avec la mise en application du plan de mobilisation générale et devient "Gare Régulatrice de Communication ", selon la désignation militaire. L'opération de diagnostic archéologique qui s'est déroulée en avril 2011 sur la commune de Marcilly-sur-Tille s'applique dans le cadre du code du patrimoine. Cet article présente les premiers résultats de cette opération archéologique inédite en Bourgogne.

\section{INDEX}

Mots-clés: Première Guerre mondiale, gare régulatrice, chemins de fer, camp militaire, céramique, militaria, verre

\section{AUTHOR}

\section{FRÉDÉRIC DEVEVEY}

Responsable d'Opération, Inrap frederic.devevey@inrap.fr 